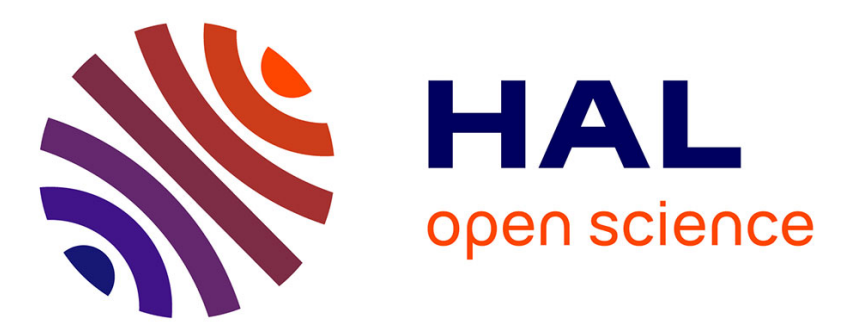

\title{
A comparative study of frictional response of shed snakeskin and human skin
}

\author{
H.A. Abdel-Aal, M. El Mansori, H. Zahouani
}

\section{To cite this version:}

H.A. Abdel-Aal, M. El Mansori, H. Zahouani. A comparative study of frictional response of shed snakeskin and human skin. Wear, 2017, 376-377 (Part A), pp.281-294. 10.1016/j.wear.2016.12.055 . hal-02416726

\section{HAL Id: hal-02416726 \\ https://hal.science/hal-02416726}

Submitted on 17 Dec 2019

HAL is a multi-disciplinary open access archive for the deposit and dissemination of scientific research documents, whether they are published or not. The documents may come from teaching and research institutions in France or abroad, or from public or private research centers.
L'archive ouverte pluridisciplinaire HAL, est destinée au dépôt et à la diffusion de documents scientifiques de niveau recherche, publiés ou non, émanant des établissements d'enseignement et de recherche français ou étrangers, des laboratoires publics ou privés. 


\title{
A comparative Study of Frictional Response of Shed Snakeskin and Human Skin
}

\author{
H. A. Abdel-Aal ${ }^{1, *}$, M. El Mansori ${ }^{2}$, H. Zahouani ${ }^{3}$
}

1. Drexel University, 3141 Chestnut St., Philadelphia, PA-USA, 19104,

* corresponding author: hisham.abdelaal@drexel.edu

2. MSMP-EA7350, Ecole Nationale Supérieure d'Arts et Métiers, 2 Cours des Arts et Métiers, Aix En Provence Cedex 1, France

3. Laboratoire de Tribology et Dynamique des Systèmes, UMR CNRS 5513, ENI Saint Etienne - Ecole Centrale de Lyon .36 Avenue Guy de Collongue, 69131 Ecully cedex. France

\begin{abstract}
Skin in biological systems, including humans, perform several synchronized tasks (mechanical, protective, tactile, sensory, etc.). Tribological function is among skin tasks and may determine the survivability of many species. Cross comparison of tribological functional traits of skin of different species, albeit interesting, is rarely encountered, if at all exists, in tribology literature. One interesting example is that of snake and human skins. This skin pair was the subject of many studies for transdermal drug delivery. Results in that context concluded that snakeskin is highly compatible with human skin despite apparent differences in surface structure and topology. The reported compatibility raises curious question of whether there exists frictional or tribological compatibility between the two skins and if so, under what conditions, and which context. In this work, we report, for the first time in open literature, results of a comprehensive comparative investigation of shed snakeskin and human skin with respect to tribological behaviour. To this end, we compared the frictional response of shed skin obtained from P. regius and human skin from different anatomical sites, gender, and age. The results imply that, in essence, the mechanisms governing the friction response of human skin are common to snake skin despite difference in chemical composition and apparent surface structure. In particular, both skin types display sensitivity to hysteresis and adhesive dissipation. Human skin, however, being more sensitive to hysteresis than snakeskin. One interesting finding of the study is that the ratio of the coefficients of friction for snake and human skin, when sliding on the same interface, depends on the reciprocal of their respective moduli of elasticity.
\end{abstract}

\section{Nomenclature}

Areal

$\mathrm{E}$

$\mathrm{E}^{*}$

$\mathrm{E}_{\mathrm{H}}$

$\mathrm{E}_{\mathrm{s}}$

$E_{c}$

$\mathrm{F}_{\mathrm{ad}}$

$\mathrm{F}_{\text {fr }}$

$F_{\text {int }}$

$\mathrm{F}_{\text {def }}$

$\mathrm{P}$

$\mathrm{R}$

$\mathrm{R}_{\mathrm{q}}$

$\mathrm{R}_{\mathrm{S}}$

$\mathrm{Sa}$

$\mathrm{S}_{\mathrm{ku}}$
Real area of contact

Modulus of Elasticity $\mathrm{Nm}^{-2}$

Composite Modulus of Elasticity $\mathrm{Nm}^{-2}$

Modulus of Elasticity for human skin $\mathrm{Nm}^{-2}$

Modulus of Elasticity for snakeskin $\mathrm{Nm}^{-2}$

Composite modulus of elasticity

Adhesive component of friction force

Friction force

Interfacial component of friction force

Deformation component of friction force

Contact force

Composite contact radius in Hertzian contact theory

Mean arithmetic value of profile roughness $(\mu \mathrm{m})$

radius of asperity

Aerial Mean arithmetic value of roughness $(\mu \mathrm{m})$

Profile Kurtosis parameter 


\section{$\mathrm{Sq}$}

Ssk

W

Acronyms

SEM

COF

RMS

TBH

WLI

\section{Greek symbols}

$\gamma$

$v$

$\mu_{\mathrm{B}}$

$\mu \mathrm{F}$

$\mu$ Dry

$\mu$ Wet

\section{Subscripts}

$\mathrm{H}$

SB

SF
Root mean square average of the roughness profile

ordinates $(\mu \mathrm{m})$

Profile skewness parameter

Normal Load

Scan Electron Microscopy

Coefficients of friction

Root Mean Square

Trailing Body Half

White light Interferograms

Shear strain

Poisson's ratio

Coefficient of friction in backward motion for

snakeskin

Coefficient of friction in forward motion for snakeskin

Coefficient of friction in dry sliding for human skin

Coefficient of friction in wet sliding for human skin

Human skin

snake backward direction

snake forward direction

\section{Introduction}

Skin in vertebrates and inter-vertebrates manifest complex composition. It comprises arrays of collagen fibers arranged in various patterns. Arrays of collagen and elastin are common in skin of many species (human, worms, fish, etc.,). Collagen fibers assume several shapes (straight, convoluted, or crimps). They are arranged in patterns of various degree of randomness [1] Despite sizeable variation in structural patterns, the stress strain curve of almost all skin types is of a universal form (the so-called J-shaped stress-strain curve) [2].

Mai and Atkins [3] analyzed the energetics of the J-curve at each interval of its evolution during tensile tests. They observed that within the early stages of this type of stress-strain curve, strain is almost independent of stress. This implied the lack of shear connection in the particular material. Lack of shear connection prevents the concentration of energy into the path of a putative crack. Lack of shear connection, equivalent to lack of shear stiffness in anisotropic solids, is the origin of high tear resistance of skin [3].

Friction is an interfacial phenomenon within which a shearing force performs work on an effective volume of two complying materials. This effective volume includes the surface layer of the skin as well as several sublayers that support the normal complying load. Dissipation of the friction-induced-work takes place within the sub-layers along a path that depends on the pattern of the fiber-elastin matrix comprising the skin. The universal behavior of the stress strain curve for the skin implies also a universal behavioral trend in shear loading and thereby in friction. That is one may anticipate that the mechanics of accommodation frictional loads in skin are universal regardless of the species.

In the past three decades or so, considerable work that probe friction behavior of human skin took place. The general motivation of these efforts varied between cosmetics [4-8], healing of burn and wounds [9-13], prosthesis [14-16], and haptics [17-21] among other things. Understanding the sense of touch and reaction of skin to fabrics was another major motivation 
[22-27]. Recently the problem of developing synthetic skin assumed considerable momentum. Several works that compare the friction of human skin to several synthetic skins started to emerge in the literature [28-34]. Tribology literature however still lacks studies where the friction behavior of skin from different species is cross-correlated. In fact, few studies that consider skin of animals or reptiles is not frequently encountered to start with. Of the existing studies, only few animal skin have been investigated (e.g. few reptiles, porcine and rat [3542]). Cross correlation of human skin performance to performance of other skin types is a very active topic within transdermal drug delivery.

A primary objective in the design and optimization of dermal or transdermal drugs is to understand the mechanics of "in-vivo" performance. When the drug is designed for humans, it is essential evaluate percutaneous absorption of molecules. The best prohibit experimentation with human subjects within the initial development stage. A challenge, therefore, arises since the option at this stage is to find a plausible correlation between "ex-vivo", animal and human studies for prediction of percutaneous absorption in humans [43]. Consequently, considerable investigations took place within the past four decades to assess the permeability of many biomaterials in comparison to human skin. The list includes, primates, porcine, rodents, guinea pigs and snakeskin (with porcine skin being frequently showing many similarities to human skin [44-51]).

Higuchi and Kans [52] were the first to propose shed snakeskin as a barrier membrane in-vitro permeation studies. Following their lead, several researchers incorporated shed snakeskins in their experimental protocols. Skin from several snake species, Elaphe obsolete [53-57], have been investigated. Haigh et al. [58] investigated the effect of species, sites and body regions of the shed snakeskin on measurements and their relation to actual performance of human skin. Haigh reported good correlation to human skin. He suggested the use of shed snakeskin as a model membrane for permeation studies despite anatomical differences and chemical compositions [54, 55, 59].

Trans-dermal diffusion is a time-dependent phenomenon that initiates at the skin surface (i.e. at the level of the micro-topography (roughness)). The process starts by the diffusing substance attempting to occupy the void space between the roughness features of the target surface. Roughness features (or micro-topographical features on the skin) have no regular or uniform geometry. Spacing between, roughness features, volume occupied by an individual feature, and shape are all different on any surface. These parameters affect the path and time of diffusion through affecting the resistance to initially filling the void space. It follows that the manner the roughness features branch to occupy their respective volume in space will determine the void volume available for the diffusing substance to occupy, and thereby initial resistance to diffusion. That is, the layout of the micro topography features on the surface of the skin maps initial resistance to diffusion. Compatibility of diffusion between two surfaces (or skin types) therefore should originate from common features in the branching of roughness. One difficulty encountered in identifying potential common metrological features is the appearance of the surface of both skin types. Abdel-aal [60] avoided this difficulty by considering the fractal structure of both skin types. That is by focusing on the growth of topographical features in space rather than on the statistical variation within the topography of the two surfaces. The analysis, thus, focused on identifying the relationship between form and volume in space then relating the findings to particular metrological features (i.e., the fractal description of the two skin types). Examination of exuviae of some 45 snake species and comparison to human skin verified that both skin types, despite displaying different surface topological features, share a narrow band of fractal dimensions $(2.55 \leq \mathrm{D} \leq 2.6)$. Sharing the 
fractal dimension explained the time compatibility of snakeskin to human skin observed in permeability experiments.

Sharing a common form of a stress-starin curve and a fractal dimension points at possible generalized tribological features between human and snake types (with potential generalization to skin in general). This work therefore aims at probing those shared aspects of the tribological response of human and snakeskin.

\section{Background}

\subsection{Structure of snake skin}

The skin of snakes has two principal layers: the "dermis" and the "epidermis". The dermis is the deeper layer of the two main layers. It comprises connective tissue containing a rich supply of blood vessels and nerves. The epidermis is composed of "strata" that contain closely packed cells. The strata consist in seven layers that form an outer protective coating of the body [61]. The first of the seven layers forming the epidermis (figure 1) is the "stratum germinativum". This is the deepest layer lining cells having the capacity for rapid division. Following this layer, six additional layers form each "epidermal generation", the old and the new skin layers. These are: the clear layer and the lacunar layer, which matures in the old skin layer as the new skin is growing beneath;

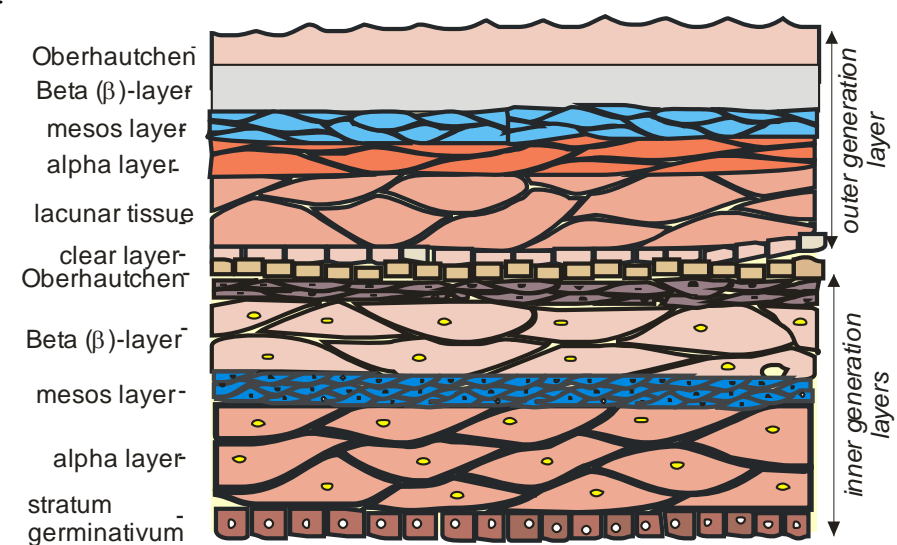

Figure 1 Generalized epidermis of a squamate reptile.

the alpha $(\alpha)$-layer, the mesos layer and the beta $(\beta)$-layer. The alpha $(\alpha)-$, the mesos layer and the beta $(\beta)$-layer consist of cells that become keratinized with the production of two types of keratin ( $\alpha$ and $\beta$ keratin). The keratinization process continuously transforms such layers into a hard protective layer. Finally, there is the "oberhautchen" layer, which forms the toughest outer most layer of keratinized dead skin cells. . The oberhautchen layer of the ventral side is also the layer that directly interacts with the substratum during locomotion. Additionally, it is the layer containing the micro-ornamentation of the skin (both the dorsal and ventral).

Snakes, like other reptiles, have a skin covered in scales of various shapes and sizes. Scales are formed by the differentiation of the snake's underlying skin or epidermis. Each scale has an outer surface and an inner surface. A snake hatches with a fixed number of scales. The scales do not increase in number as the snake matures nor do they reduce in number over time. The scales however grow larger and may change shape with each molt. In snakes cell division, in the "stratum germinativum", occurs periodically [62], and leads to the replacement of all the layers above the area where cell division takes place. The reptile, therefore, grows a second skin underneath the old skin, and then "sheds" the old one. About two weeks before the reptile sheds its skin, the cells in the stratum germinativum begin active growth and a second set of layers form slowly underneath the old ones. Following such a process, the cells in the lowest 
layers of the old skin, the clear and the lacunar layers, and the Oberhautchen layer of the skin below undergo a final maturation and a so called "shedding complex forms". Fluid is exuded and forms a thin liquid layer between them. Enzymes, in this fluid, break down the connections between the two layers, the old skin lifts and the reptile actively removes it.

\subsection{Structure of human Skin}

The human skin is a soft biomaterial that manifests a sophisticated hierarchical structure [63]. Similar to reptilian skin, human skin encases the entire human body and its internal organs. It is the organ of the largest surface area in a human body (covers around $1.6-2 \mathrm{~m}^{2}$ in adults and accounts for approximately $16 \%$ of a person's weight [64]. The skin is composed of three anatomically distinct functional layers (figure 2): the epidermis, the dermis and the hypodermis.

A human epidermal layer represents the main barrier between the body and its surroundings. This layer performs the principal skin protective actions (i.e., its function is similar to the oberhautchen layer in a snake). The thickness of a human epidermis ranges between 0.027 and $0.15 \mathrm{~mm}$ depending on the particular body cite examined. The epidermis mostly comprises dead cells. These originate within the lower regions then are pushed by newly generated cells. The outermost layer of the epidermis is the "stratum corneum", which provides primary protection for the skin. This region, only 10-20 $\mu \mathrm{m}$ thick, acts as the primary barrier to the percutaneous absorption of compounds as well as to water loss. Underlying the stratum corneum is the viable epidermis $(50-100 \mu \mathrm{m}$ thick), which is responsible for generation of the stratum corneum. The dermis (1-2 mm thick) is directly adjacent to the epidermis and provides the mechanical support for the skin. The viable epidermis is a stratified epithelium consisting of basal, spinous and granular cell layers. Each layer is defined by position, shape, morphology and state of differentiation of keratinocytes. The keratinocyte synthesize and express numerous different structural proteins and lipids during their maturation. The last sequences of the keratinocyte differentiation result in their transformation into chemically and physically resistant cornified squames of the stratum corneum, called corneocytes. In this context, keratinization for protective functionality, the dynamics of the epidermis in humans is similar to the alpha $(\alpha)$ mesos, and the beta $(\beta)$ layers in snakeskin.

The second layer within the human skin is the "dermis". This is a layer of variable thickness (between 0.6-3 mm). It comprises dense, irregular connective tissue, nerve, and blood vessels. A human dermal layer comprises two sub layers: the papillary and the reticular dermis. The dermis confers firmness, high elasticity/ resilience, tensile strength and tear resistance to the skin [65]. The "hypodermis" is the innermost layer of the skin. It contains over $50 \%$ of the total body fat. It is composed of loose elastic and adipose tissues and has two main functions: firstly as a strong connection layer between the skin and the muscles or bones beneath, and secondly for thermal insulation purposes. It also serves as a protective layer by absorbing impacts from the outside that could result in internal damage for nerve endings and blood vessels.

\section{Materials and methods}

The current study examined shed skin from Royal Python (P. regius). Table 1 presents a summary of species taxonomy and major dimensional features

Table 1 summary of species taxonomy and major dimensional features

\begin{tabular}{ll}
\hline & P. regius \\
\hline Family & Pythonidae \\
Subfamily & Python \\
Genus & P. regius
\end{tabular}


Length $(\mathrm{cm})$

Number of ventral scales

Ratio of length to maximum diameter

Mass (Kg)

Average area of ventral scale $\mathrm{mm}^{2}$

Maximum length of fibrils $(\mu \mathrm{m})$

Maximum ventral scale aspect ratio

Minimum Ventral scale aspect ratio
150

208

10.2

1.3

102.35

1

3.142

1.75

General features of the species were described elsewhere [39]. Figure 3 meanwhile, details the micro features of the skin on the dorsal and ventral sides.

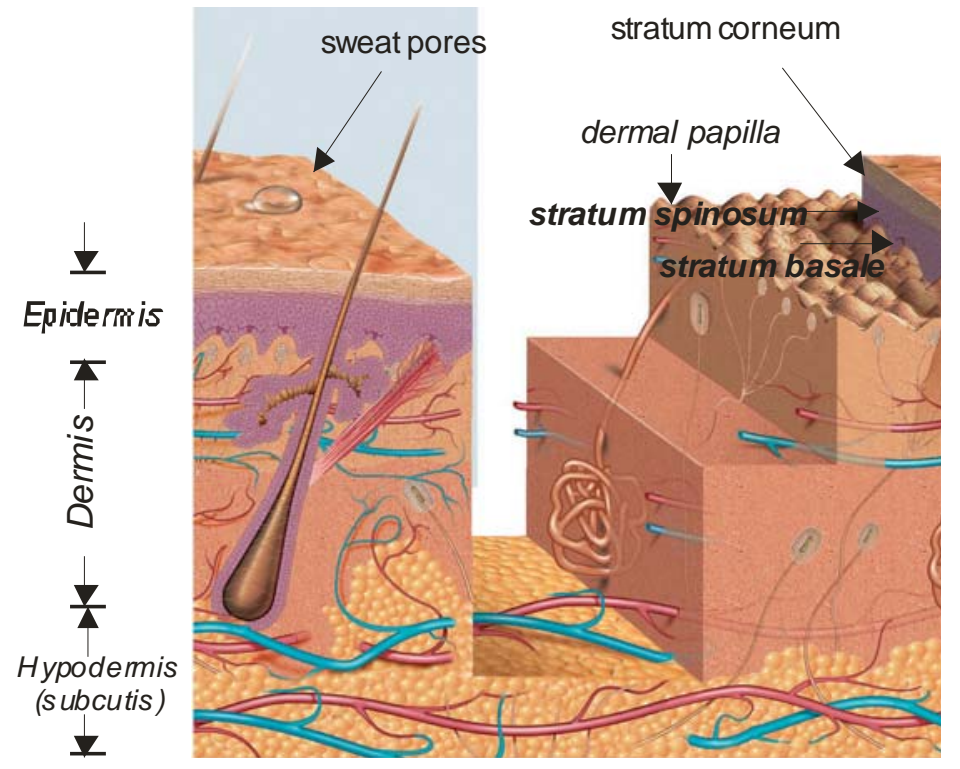

Figure 2: A schematic drawing of the layered structure of human skin. The figure depicts both a projection view and a skin cross-sectional isometric view of the various skin layers

The exuvium surface geometry of shed snake epidermis does not differ from that of a live animal $[42,66,67]$. Therefore, the shed skin of snakes reflects the frictional response of the live animal. Furthermore, the shed skin reflects the metrological surface and textural features of the live animal.

Data for human skin entailed analysis and characterization of the skin of a group of volunteers. The groups were as follows: Caucasian women ages 30 to 40 years, Young Caucasian boys (46 years old), and African boys (5-8 years old).

The main purpose of the study is the cross-correlation of friction response of the skin types examined. The detailed metrological comparison between the two skin types is therefore out of the scope of this presentation. However, to provide a generalized view of the metrological structure and differences between the two skin types we included representative data. This data reflect the general trends of the roughness features of each surface. The sites chosen for presentation differ due to the nature of function of the species (human VS snake). For snakes the ventral parts are principally friction sites. They are used in locomotion and gripping. For humans not all the sites are used for locomotion or gripping, yet most of the sites undergo friction be it permanently or occasionally. As such we elected to sample human skin metrology through the analysis of roughness of a generalized site rather than a specialized one (until the time of a comprehensive study between the locomotry cites in both skin types i.e. ventral sites 
in snakes and underfoot and inner palm (for example in humans). Evaluation of metrological texture parameters utilised a white light interferometer (WYKO 3300 3D automated optical profiler system). Analysis of all resulting White light..

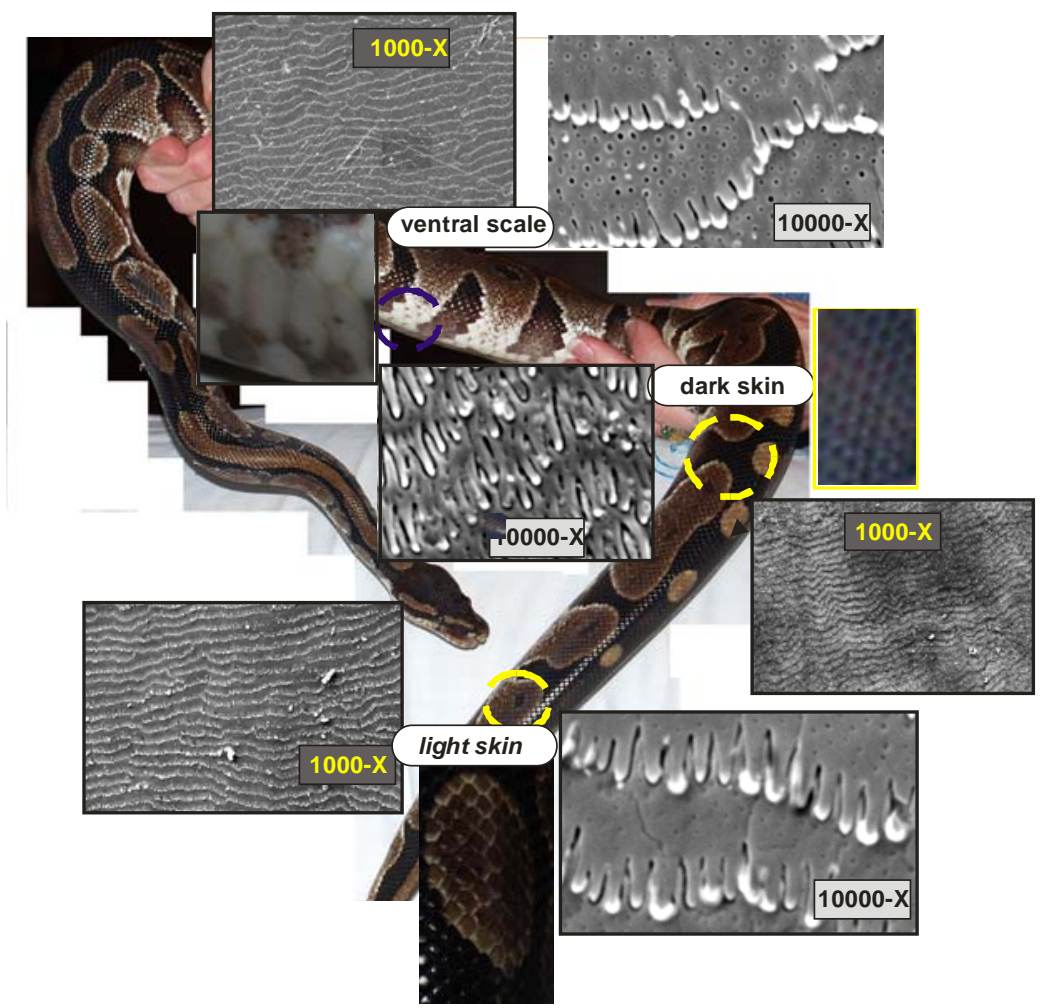

Figure 3. General appearance of the P. Regius and SEM details of the three skin colors of the species: Dorsal skin light colored, Dorsal skin dark colored and the Ventral skin. All observations were performed on a JEOL JSM-5510LV SEM using an acceleration voltage that ranged between $4 \mathrm{kv} \leq \mathrm{V} \leq 6 \mathrm{Kv}$ ).

Interferograms, WLI, to extract the surface parameters used two software packages: Vision ${ }^{\circledR} \mathrm{V}$. 3.6 and Mountains ${ }^{\circledR}$ v 6.0 .

To determine the metrological features of shed snakeskin, we identified 16 regions on the hide of each of the studied snakes. Each of the examined spots comprised a section that is approximately $2.5 \mathrm{~cm}$ wide. Five interferograms were recorded for each of the dorsal and the ventral sides of the chosen region on the skin and these were analyzed to extract the surface texture parameters. Sample representative results of the metrological parameters for shed snakeskin and human skin are presented in figures 4 and 5. Each of the figures depicts six plots. The first, labeled a, shows the original-raw- white light interferogram of the particular skin sample. Following this plot, the figure labeled b presents the surface isotropy plot. The last four plots, labeled $\mathrm{c}$ through $\mathrm{f}$, present the roughness profile extraction of the skin sample in four directions (AE-PE, LL-RL, AR-PL, AL-PR). 

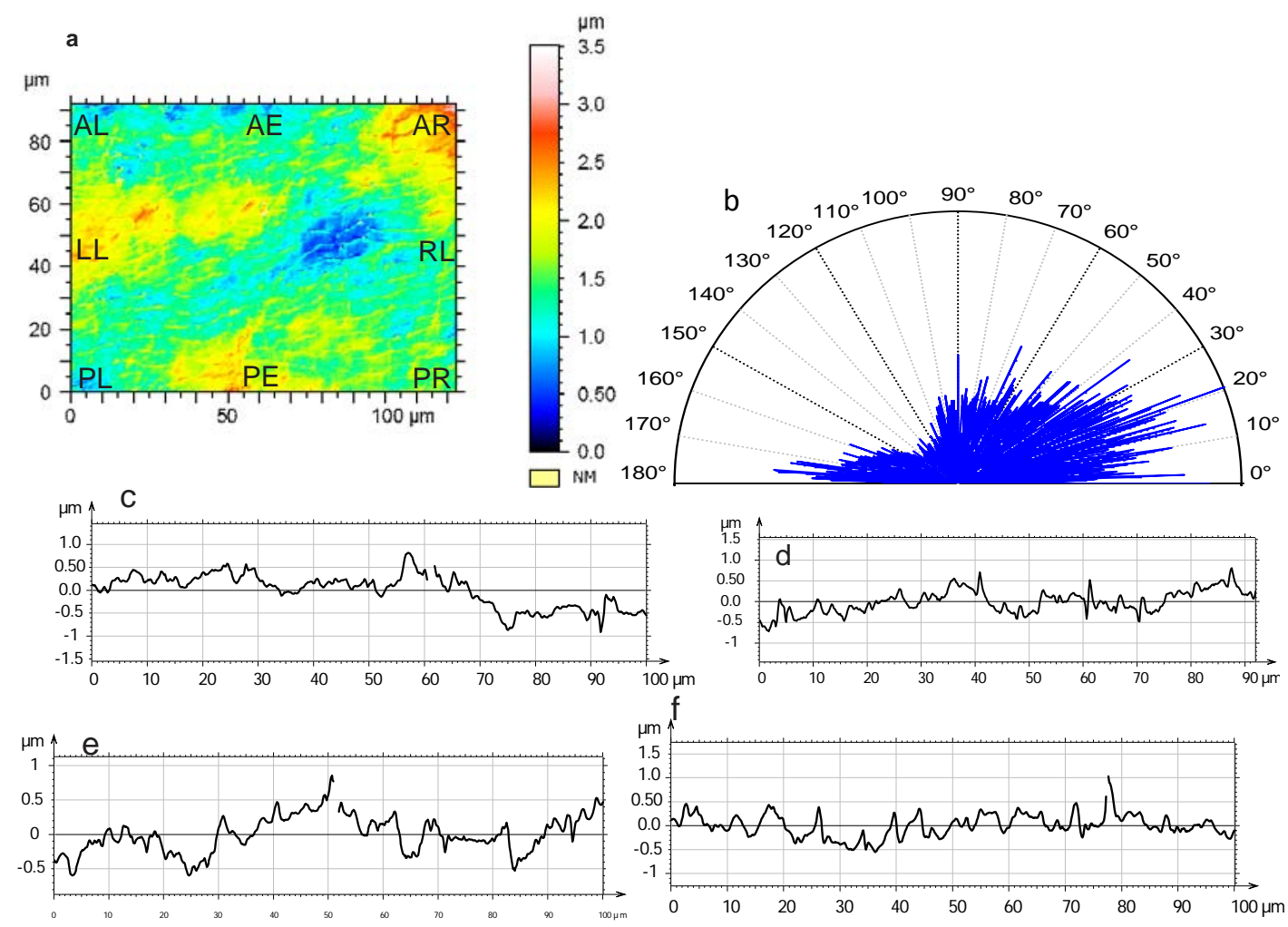

Figure 4 Metrological data extraction for shed python skin. Figure 4-a, original white light interferogram, b) surface isotropy plot, c) roughness profile extraction in the anterior posterior direction (AE-PE), d) roughness profile extraction in the lateral direction (LL-RL), e) roughness profile extraction in the diagonal direction (AL-PR), and f) roughness profile extraction in the diagonal direction (AR-PL).

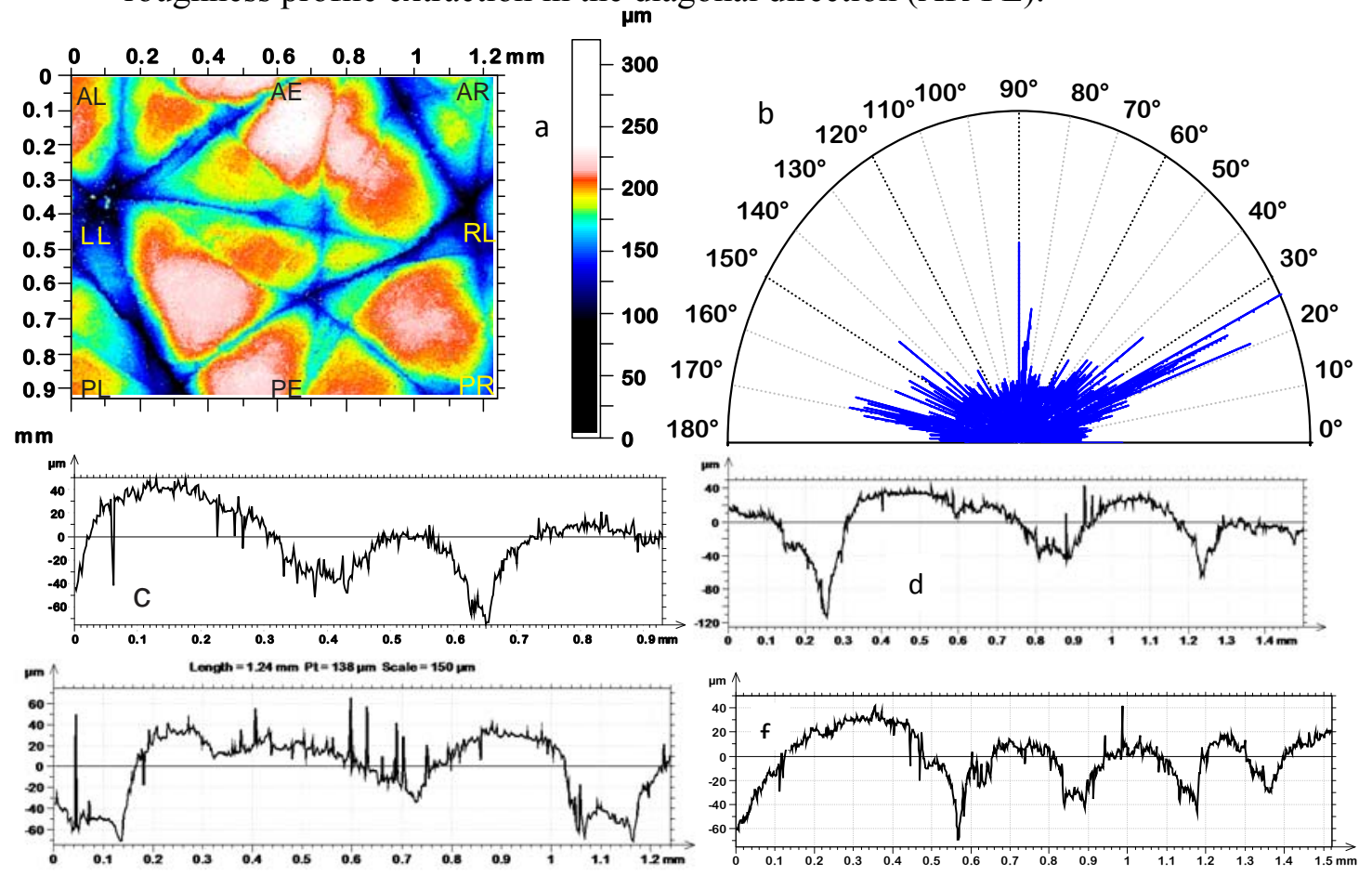


Figure 5 Metrological data extraction for Human skin. Figure 4-a, original white light interferogram, $b$ ) surface isotropy plot, $c$ ) roughness profile extraction in the anterior posterior direction $(A E-P E), d)$ roughness profile extraction in the lateral direction $(L L-R L), e)$ roughness profile extraction in the diagonal direction $(A L-P R)$, and $f)$ roughness profile extraction in the diagonal direction (AR-PL).

It is noted that in general the texture of both skin types does not show significant dominant angle (for both skis the so called isotropy index $S_{\text {tr }}$ falls in the interval $0.21 \leq S_{t r} \leq 0.6$ for python skin and $0.2 \leq \mathrm{S}_{\mathrm{tr}} \leq 0.261$ for human skin).

Roughness profiles, however, differ by direction. Table 2, which presents the so-called Aerial parameters of the skin support this remark. Observe for example that the root mean square, and the mean value of the roughness, Sa and Sq, for snakeskin represent a small fraction of the values pertaining to human skin. More interesting is the comparison of the Kurtosis and Skewness, $\mathrm{S}_{\mathrm{ku}}$ and $\mathrm{S}_{\mathrm{sk}}$ parameters of the skin types.

The kurtoses for snakeskin and for the woman group are almost equal numerically and imply a Gaussian distribution of the roughness. Young human skin (Caucasian and African) manifests high values. The skewness of snakeskin is positive and is opposite in sign to skewness of human skin. The combination of positive kurtosis-positive skewness (snakeskin) implies a surface dominated by peaks, whereas a positive-negative combination implies a surface dominated by valleys. This arrangement is not universal in snakes but depends on the habitual function of the particular species [39]. In case of P. regius it facilitates ventral arboreal gripping.

Table 2 Summary values of extracted metrological parameters for snakeskin and human skin.

\begin{tabular}{lllll}
\hline Parameter & Snake & Woman & A Boy & C Boy \\
\hline $\mathrm{S}_{\mathrm{a}} \mu \mathrm{m}$ & 0.293 & 25.2 & 16.1 & 24.7 \\
$\mathrm{~S}_{\mathrm{q}} \mu \mathrm{m}$ & 0.373 & 31.7 & 21.4 & 33.3 \\
$\mathrm{~S}_{\mathrm{ku}}$ & 3.37 & 3.36 & 6.16 & 5.70 \\
$\mathrm{~S}_{\mathrm{sk}}$ & 0.322 & -0.773 & -0.706 & -0.574 \\
\hline
\end{tabular}

\section{$2.3 \quad$ Friction measurements}

\subsubsection{Snake skin}

Frictional behavior of the shed snakeskin was characterized by a bio-tribometer [68]. The active data collection element in the device comprises a thin nitrocellulose spherical membrane; $40 \mathrm{~mm}$ in diameter, with approximate thickness $0.2 \mathrm{~mm}$. Table 3 provides a summary of the properties of the probe and the experimental conditions.

In a typical experimental run, the skin remains stationary and the tribo-probe moves with an average speed of $20 \mathrm{~mm} / \mathrm{s}$ using a normal force of $0.5( \pm 0.05) \mathrm{N}$. The skin used in measurements consisted of $100 \mathrm{~mm}$ long patches taken from four locations on the ventral side of the shed skin. Skin samples did not receive any chemical or physical treatment.

Table 3 summary of contact probe characteristics and experimental conditions

\begin{tabular}{ll}
$\begin{array}{l}\text { Probe } \\
\text { Geometry } \\
\text { material }\end{array}$ & $\begin{array}{l}\text { Sphere } \\
\text { nitrocellulose }\end{array}$ \\
$\begin{array}{l}\text { Dimensions } \\
\text { Thickness }\end{array}$ & $\approx 0.2 \mathrm{~mm}$ \\
$\begin{array}{l}\text { Diameter } \\
\text { Mechanical Properties }\end{array}$ & $40 \mathrm{~mm}$ \\
Young's Modulus & $1 \mathrm{Gpa}$ \\
\hline
\end{tabular}




\section{Surface roughness}

$\mathrm{Ra}$

$\mathrm{Rz}$

Experimental conditions

Sliding speed

Nominal contact force
$4 \mu \mathrm{m}$

$31 \mu \mathrm{m}$

$20 \mathrm{~mm} / \mathrm{s}$

$0.5( \pm 0.05) \mathrm{N}$

To mimic the effect of the snake body we ran a series of experiments with a flexible siliconepadding cushioning the skin. Before starting an experiment, the particular skin patch was placed on a rectangular elastic pad of dimensions length $\mathrm{L}=100 \mathrm{~mm}$, width $\mathrm{W}=75 \mathrm{~mm}$ and of approximate thickness $4 \mathrm{~mm}$. The pad is made of silicone rubber (Silflo ${ }^{\circledR}{ }^{\mathrm{TM}}$, Flexico Developments Ltd., Potters Bar, UK). Table 4 provides a summary of the pad material properties. Measurement of the friction forces proceeded along the two major body axes: the anterior-posterior axis (AE-PE), and the lateral axis (LL-RL). Measurements were recorded in the forward and backward directions along both axis (i.e, going from the AE to the PE and converse and from the LL side to the RL and converse).

Table 4: Summary of geometric dimensions and mechanical properties of elastic pads used to cushion skin in experiments.

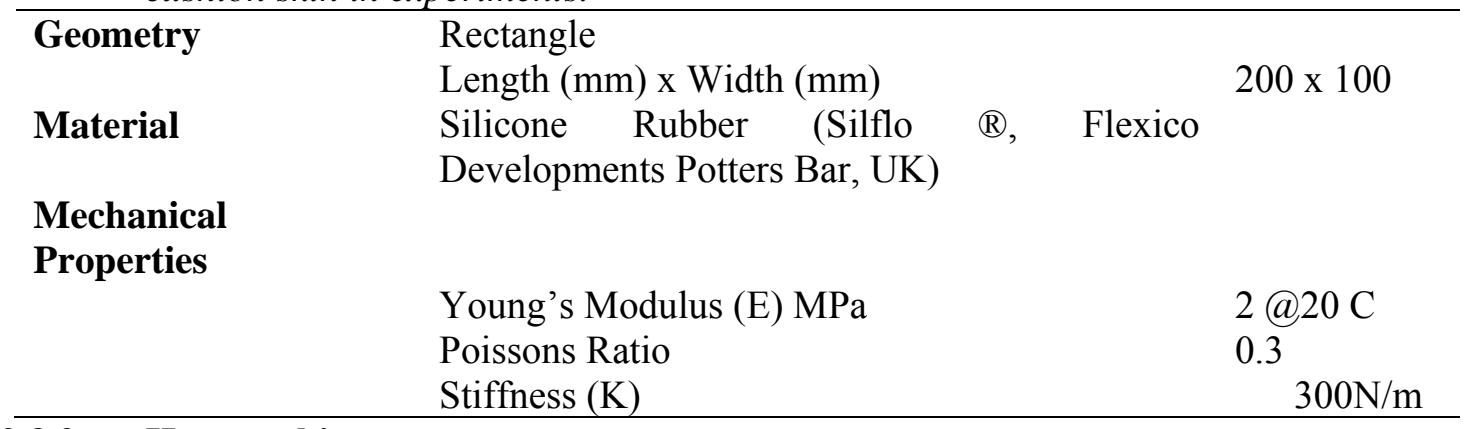

\subsubsection{Human skin}

Friction of human skin, in theory, is a function of hydration, anatomical site, age, gender, and race. Many researchers investigated the effects of these factors. Cua and Elsner [69,70] pointed the significant influence of anatomical site on the COF. Influence of race, age, and gender, however, remains inconclusive. Elsner [70] and Asserin [71], for example, did not observe age related differences when examining the friction of the volar forearm. Cue et al. did not report significant differences in friction of skin based on gender. Manuskiatti et al [72] examined roughness and friction of human skin as a function of race (Black VS Caucasian). Again, these researchers were not able to isolate a significant race-based influence. In addition, to the knowledge of the authors, to date, reports that indicate the existence of frictional anisotropy in human skin are non-existent within open literature. Given such a background, our experimental protocol did not entail provisions to investigate the effect of race, age or gender induced influences on frictional behavior of human skin. Rather, our procedure focused on measuring the COF of test subjects only as a function of variation in anatomical site and hydration.

All friction measurements for human skin were obtained using the same tribo-probe used for measuring snakeskin under the same experimental conditions (load and sliding speed).

The sites used for friction measurements comprised the principal sites within the human body (legs, Knee, face, arms). In this study only repeatable and consistent data are reported. The condition of repeatability confined site data to those shown in what follows.

\section{Results}


The skin responds distinctly to the combination of surface geometry, material property, and the mechanical contact parameters of the substratum. Frictional response of the skin, therefore, is a complex phenomenon that depends not only on the process parameters, but also on the individual interaction between these parameters. This complexity reflects on the manner and scope of presenting the results of any investigation of skin friction. Bearing this in mind, presentation of results in this work will not cover every aspect of the tribology of snake and human skins. Rather within the following sub-sections, we report on those findings that are most relevant to the comparison process (which is the main subject of this work). The sequence of presentation starts with exposition of the data obtained for snakeskin followed by presenting data of human skin.

\subsection{Snake Skin}

Figure 6 presents a collective plot that traces the repeatability of COF values obtained. Circles represent the COF obtained in each measurement run. Square symbols denote average values along with associated standard deviation of data. The data shown in the plot depict measurements obtained in dry and wet sliding modes of the leading half of the Python ventral skin. Measurements proceeded along two principal directions. The first, termed here as forward motion, represents motion in straight line along the anteroposterior axis of the reptile, however, going toward the cranial end of the reptile). Moving toward the caudal end of the reptile along the anteroposterior axis is termed here as backward motion.

The COF in backward motion is greater than the COF obtained in forward motion (i.e., $\mu_{\mathrm{B}}>\mu_{\mathrm{F}}$ ), in each of the friction modes wet and dry, which manifests frictional anisotropy. This result is consistent with the findings of several authors [38, 73-78]. The anisotropy in friction of snakes partially emanates from the geometrical structure of the individual micro-fibrils [79]. Measurements in wet mode for forward motion, however, yield friction coefficient values that are higher than those obtained in dry mode. In backward motion, however, values of the COF are lower in case of wet skin. In both cases, wet and dry, the forward motion COF is less than that in backward motion.

Figure 7 presents a collective plot of the COF obtained in various experimental runs, and the average value, for the dorsal and ventral sides of the leading half of the Python (mid-section to head region). The plot compares friction in the forward and backward directions for the dorsal and ventral sides in dry sliding. The dorsal scales show higher COF than the ventral scales. Such a result is consistent with the findings of Berthe et al [78], who confirmed the higher friction of the dorsal scales of C. hortulanus (Amazon tree boa).

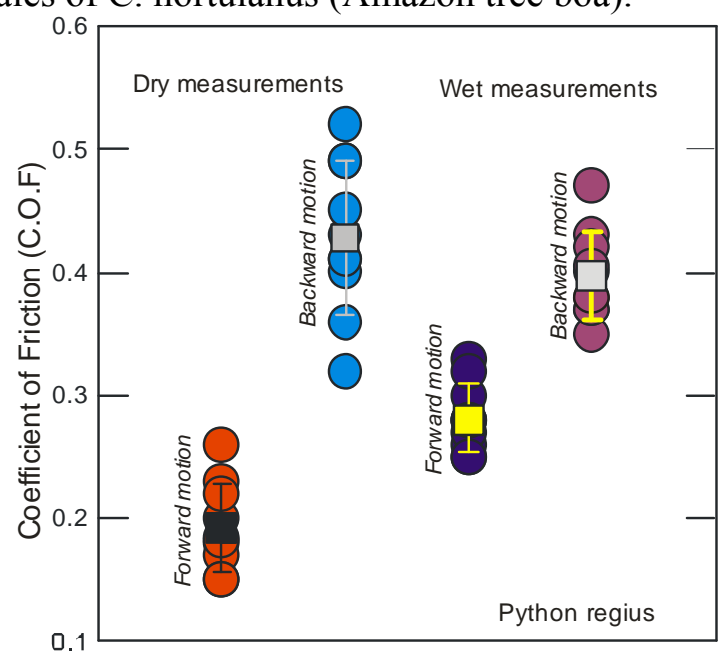


Figure 6 Variation and scatter of COF measurements for skin of the P. regius in dry and wet sliding conditions, for different experimental runs, obtained by the tribo-acoustic probe method. Forward motion indicates sliding in AE-PE direction (tail to head); Backward motion implies motion from head to tail (PE-AE). Circles indicate values obtained in different measurement runs, whereas hexagonal symbols denote average values along with their respective standard deviation.

Measurements also manifest the frictional anisotropy between forward and backward motion reflected in figure 6. Figure 8 provides a comparative bar plot of the average "static" COF for P. regius in forward and backward motion. The numerical values of the bars represent the statistical mean of the COF obtained from all spots on the hide.

\subsection{Human skin}

Figure 9, presents a comparative summary of measurements obtained for human skin. The figure presents two plots (each comparing the COF of the skin in a particular sliding mode). Figure 9-a, depicts a bar plot of data obtained in dry sliding mode, whereas figure 9-b, plots data obtained in wet mode. In obtaining wet mode measurements, we made no provisions to determine skin moisture content. The procedure entailed rubbing the skin spot of interest with a moist paper towel, then applying the measuring device. As such, values of the COF presented as figure $9-b$ are to be considered as general indicators of the behavior.

The plot generally confirms the variation of the COF with anatomical site (both in wet as well as in dry measurements). Values of the COF vary considerably between locations. The COF value for the knee, for example, is roughly four times the COF value for the check in dry mode. In all, COF measurements obtained in wet mode imply higher values than measurements

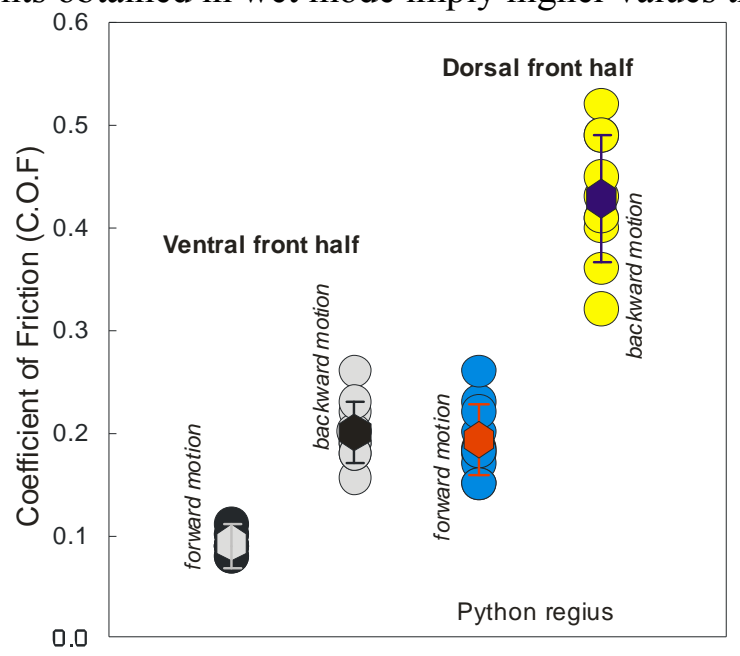

Figure 7 Scatter and comparison of the COF values obtained for skin located at the dorsal and ventral sides of the front half of a P. regius. Measurements are depicted for Forward (tail-to-head) motion and the converse. Circles indicate values obtained in different measurement runs, whereas hexagonal symbols denote average values along with their respective standard deviation. 


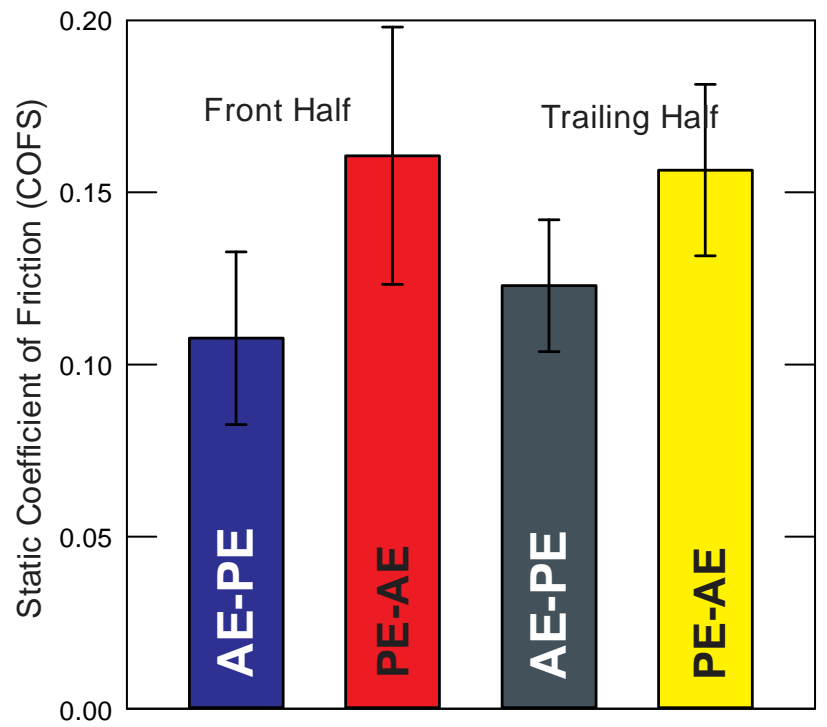

Figure 8 Comparison between the average values of the static ventral COF obtained for the $P$. regius.

obtained in dry mode. Due to the statistical constraints set in this work, a one-to-one comparison between the COF for the same anatomical location is not possible. As such, the following observations are to be accepted with caution.

For the cheek, the COF in dry mode is almost one third of the COF value obtained in wet mode. The difference between the COF values for dorsal forearm, in wet and dry friction, is not as pronounced as in the case of the cheek (value of the wet COF is still higher than that in dry sliding). So that, while wet measurements are consistently higher than dry measurements, the data do not allow the identification of a unique relationship that correlates wet and dry COF values. This is due to the limited scope of the investigation. Never the less, the data reflect dependence of the COF for human skin on the anatomical cite examined. One also has to keep in mind that hydration in this study was imposed on the skin using water for which human skin has a complex tribological response. The forces developed in water-based lubrication of the skin depend on the topography of the anatomical site and on the thickness of the water meniscus developing on the skin. The thickness of the water meniscus determines whether water would induce a lubricating effect or, alternatively, it will induce an additional adhesive component to the COF. Data presented in figure 9 imply that for the experimental conditions examined in work, water induces adhesion to the COF. This adhesive contribution leads to a higher COF in wet sliding than in dry sliding (i.e., $\mu_{\mathrm{wet}}>\mu_{\mathrm{dry}}$ ). 

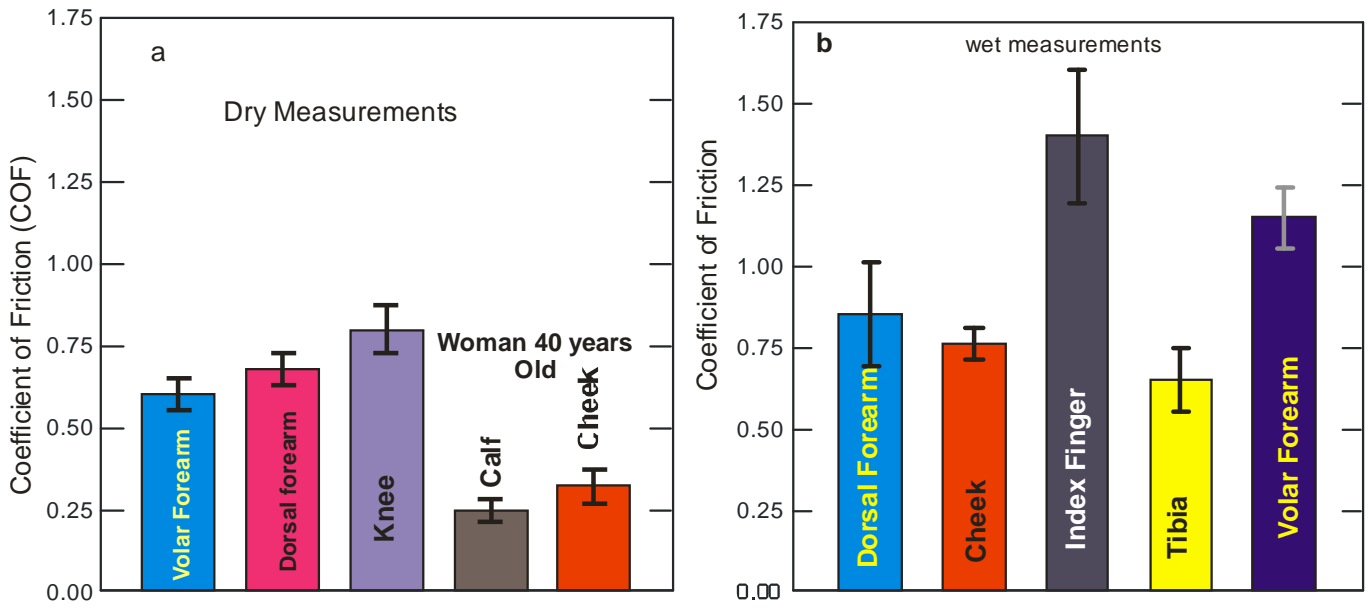

Figure 9 Comparison between local COF of human skin for dry and hydrated conditions.

It is interesting to note that the index finger and the volar forearm manifest significantly high frictional resistance in the wet mode $\left(\mu_{\mathrm{wet}}>1\right)$. In addition to the presence of moisture, such a high COF may originate from the unique deformation mechanics of skin of that particular location, where topography and stiffness play considerable role in generation of frictional tractions.

To address the limitations induced by repeatability of data we include tables 5 and 6 . The tables present summary COF values of human skin extracted from literature. Table 5 provides frictional data for human skin against different materials in dynamic and static modes. Table 6, meanwhile presents frictional data as a function of skin condition (i.e. wet or dry). Comparison of values plotted in figure 9, with those of tables six and seven reveals very good agreement.

Table 5: COF data for human skin, from different anatomical sites, in dry friction against different materials in dynamic and static modes

\begin{tabular}{|c|c|c|c|c|c|}
\hline \multirow[b]{2}{*}{ location } & \multicolumn{4}{|c|}{ Dynamic Measurements Static Measurements } & \multirow[t]{2}{*}{ Reference } \\
\hline & material-subs & $\mu \mathrm{D}$ & substrate & $\mu \mathrm{s}$ & \\
\hline forehead & Teflon & 0.373 & & & \\
\hline upper arm & & 0.33 & & & \\
\hline volar forearm & & 0.46 & & & \\
\hline dorsal forearm & & 0.455 & & & \\
\hline Post aurcular & & 0.161 & & & [69] \\
\hline palm & & 0.57 & & & \\
\hline \multirow[t]{9}{*}{ Average } & & 0.38 & Teflon & 0.2 & [79] \\
\hline & & & nylon & 0.45 & \\
\hline & & & polyethylene & 0.3 & \\
\hline & & & wool & 0.4 & \\
\hline & & & polyethylene & $0.5-0.6$ & {$[80]$} \\
\hline & glass & 0.4 & glass & & [81] \\
\hline & s. steel & $0.2-0.4$ & & & \\
\hline & & $0.3-0.6$ & & & \\
\hline & & & Ruby & 0.7 & [71] \\
\hline
\end{tabular}




\begin{tabular}{lllr} 
& & Glass & $0.3-0.4[82]$ \\
forearm & teflon & 0.48 & \\
Post forearm & & 0.43 & \\
Ant. forearm & & & \\
dorsum of hand & 0.46 & \\
& Alumium & 0.47 & \\
& Nylon & 0.37 & \\
& Silicone & 0.61 & \\
& Cotton Sock & 0.51 & \\
& Pelite & 0.45 & \\
\hline
\end{tabular}

Table 6 COF data for human skin, from different anatomical sites, in dry friction against different materials in dynamic and static modes as a function of moisture (wet or dry)

\begin{tabular}{|c|c|c|c|c|}
\hline Skin area & Skin condition & COF & Probe/material & Reference \\
\hline \multirow[t]{3}{*}{ Calf } & Dry (untreated) & 0.5 & PE sphere & [80] \\
\hline & Wet (sweating) & 1.0 & & \\
\hline & Dry (cleaned) & $0.18-0.72$ & PE sphere & [83] \\
\hline \multirow[t]{8}{*}{ Forearm } & Dry (normal) & 1.63 & Steel sphere & [84] \\
\hline & & 0.41 & Steel slider & [85] \\
\hline & & 0.9 & Gold cylinder & [86] \\
\hline & Dry (untreated) & $0.45-0.65$ & Copper cylinder & [87] \\
\hline & Dry (cleaned) & 0.24 & Steel wires & [88] \\
\hline & & $0.37-0.8$ & Copper cylinder & [83] \\
\hline & Wet (occluded) & 1.0 & Copper cylinder & [87] \\
\hline & Wet (hydrated) & 0.71 & Steel slider & [85] \\
\hline \multirow[t]{3}{*}{ Cheek } & Dry (normal) & $0.12-0.22$ & Teflon wheel & [89] \\
\hline & Dry (washed) & $0.3-0.85$ & Aluminum ring, PTFE ring & [90] \\
\hline & $\begin{array}{l}\text { Wet (humid } \\
\text { climate) }\end{array}$ & $0.925-2.1$ & Aluminum ring, PTFE ring & {$[90]$} \\
\hline \multirow[t]{7}{*}{ Index finger } & Dry (untreated) & 0.49 & Glass & [91] \\
\hline & & 0.7 & Rubber glove & [92] \\
\hline & Dry (cleaned) & $0.6-1.75$ & Glass, paper, steel & [93] \\
\hline & Dry (washed) & 0.38 & Paper & [94] \\
\hline & Dry (washed) & $0.63-1.1$ & Polyester sheets & [95] \\
\hline & & $0.33-0.96$ & Cotton, Polyester, rayon, & [96] \\
\hline & Wet (water) & 1.2 & Rubber glove & [92] \\
\hline
\end{tabular}

\section{Discussion}

In discussing the results obtained in this work, for both types of skin, we first present the obtained values of the coefficients of friction. Thereafter, we analyze the findings to predict the tribological behavior and identify common as well as opposite traits.

5.1. Frictional behavior

Figure 10, presents a summary bar plot that collects all the measured COF values for human and $\mathrm{P}$. regius skins in dry friction. The plot presents the COF for human skin by anatomical site. For Python skin, labeled P, the figure presents three COF values. These are COF for the 
front half of the ventral skin (FH), the trailing half of the ventral skin (TH), and the average values for the Dorsal side (D). For example, the bar labeled FHF represents the value of the $\mathrm{COF}$ in forward motion averaged over the front ventral half of the reptile. Similarly, the label (THB) stands for the COF in backward motion averaged over the trailing half of the reptile.

The COF values reflect wide variation. In general, a unified trend that governs the data is not easy to identify. However, individually, some anatomical sites may share COF values. For example, the COF for the cheek and calf of the human skin are close to the COF value of the ventral front half (FHF), and that for the dorsal side of the Python in backward motion (DB).

The friction of dry skin differs from that of wet skin. The main distinction is that friction of dry skin, as a first approximation, resembles the friction of solids where the COF does not depend on the apparent area of contact. In such a case the surface roughness of the particular anatomical site and the load, are the only factors influencing friction. Dependence on external load affects the real area of contact, which in turn depends on the roughness of the particular site within the body. Moreover, the skin being essentially a viscoelastic material will deform according to the stiffness of the contact between the acoustic probe and the underlying cushion under the skin. To verify this assumption we performed an extra set of experiments where the thickness of the pad underneath the skin varied from $4 \mathrm{~mm}$ to $6 \mathrm{~mm}$ resulting in an increase in the stiffness of the contact from $300 \mathrm{~N} / \mathrm{m}$ to $500 \mathrm{~N} / \mathrm{m}$. The COF was recorded for both cases, high stiffness and low stiffness, and the results are shown in figure 11. Values plotted in the figure are average values in the sense of being the average of the values obtained on both halves of the ventral side of the reptile. For comparison, we include the values for the human calf and cheek since they are the anatomical sites of which sliding resulted in a COF close to that of the snakeskin. The plot depicts values for the COF in forward and in backward motion. The data show that higher stiffness of the underlying cushion to the skin results in lower COF. This result points at the effect of contact stiffness on skin friction. Consequently, the local stiffness of an anatomical site will influence the frictional response of the skin.

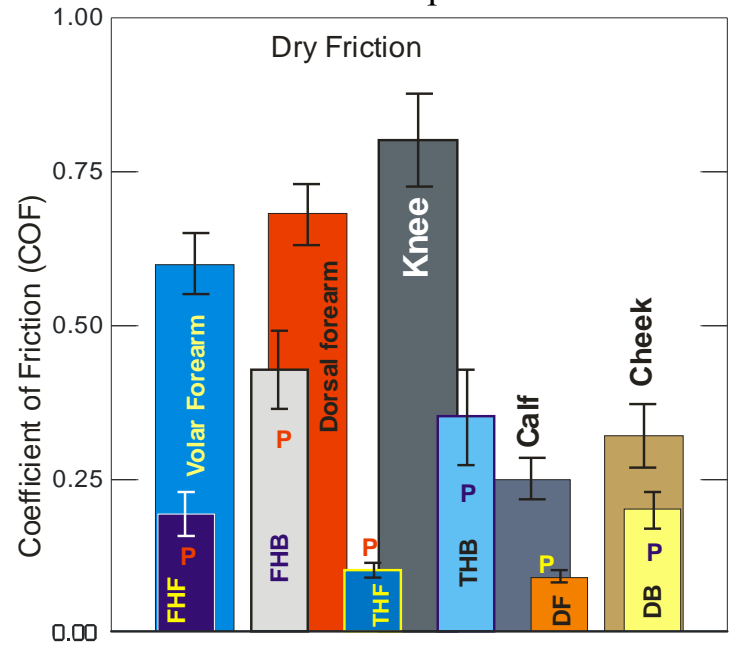

Figure 10 Comparison of COF of human skin, from two zones (calf and cheek), with the COF of python skin (in SF and SB sliding directions).

\subsection{Effect of hysteresis}

Deformation of skin and subsurface tissue during friction can contribute to the friction coefficient in the form of viscoelastic hysteresis or ploughing [4]. The contribution to hysteresis increases with normal load and contact pressure. Contact pressure, in turn, is a function of the surface roughness of the skin. So in order to check which of the skin types is 
more likely to entertain larger hysteresis contribution, it is of interest to evaluate, at least, qualitatively, which skin type develops a higher contact pressure under the action of the same nominal normal load. For such a purpose, we invoke the well known Greenwood-Williamson contact model [97].

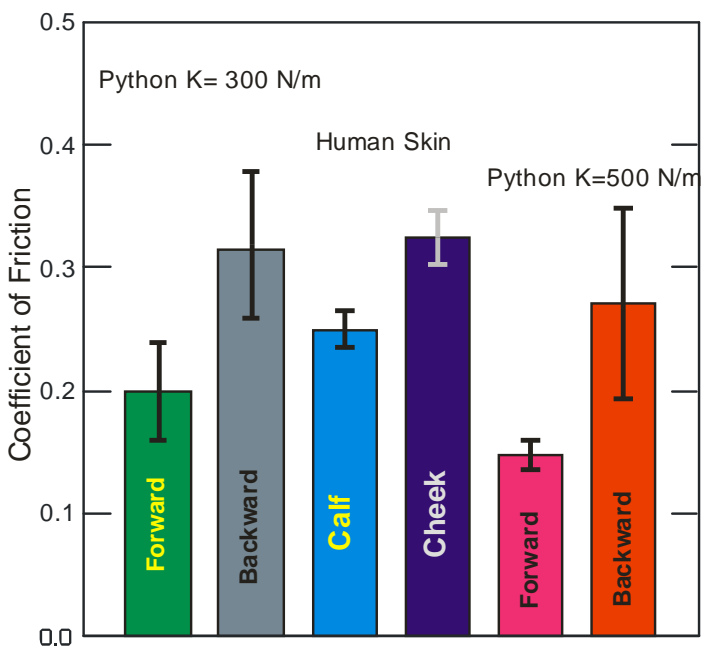

Figure 11 Effect of the stiffness of the contact between the acoustic probe and the underlying cushion under the skin on the COF of reptilian skin ( $P$. regius). Values for human skin is included for comparison.

The model assumes that the surface roughness has a constant radius $\left(\mathrm{R}_{\mathrm{s}}\right)$ and that the heights of the roughness elements follow a Gaussian distribution. For elastic deformation of the roughness elements, the contact load over a circular contact spot (similar to that established due to the contact between the acoustic probe and the skin) s given by:

$$
P(d)=\frac{4}{3} \eta A_{n} E^{*} \sqrt{R_{s}} \int_{d}^{\infty}(Z-d)^{\frac{3}{2}} \phi(Z) d Z
$$

For Gaussian distribution, there is no closed form solution for equation (1). Shi and Polycarpou [98], showed that an approximation to the Gaussian distribution assumed in equation (1) is an exponential roughness height distribution of the form,

$$
\phi=C \exp \left[-\frac{\lambda d}{R_{q}}\right]
$$

Where $\mathrm{C}$ and $\lambda$ are constants of values 17 and 3 respectively. Adopting the distribution of equation two simplifies the integration and therefore allows a closed form solution of equation one. Accordingly, for an exponential height distribution and elastic contact conditions, the contact force will be given by,

$$
P(d)=\frac{C \sqrt{\pi}}{\lambda^{\frac{5}{2}}} \beta A_{n} E^{*}\left(\frac{R_{q}}{R_{s}}\right)^{\frac{1}{2}} \exp \left(-\frac{\lambda d}{R_{q}}\right)
$$

Equation 3 emphasizes the influence of the roughness of the skin surface on the magnitude and distribution of the pressure acting on the skin in dry friction. This equation may be rearranged to express the contact pressure explicitly in terms of standard surface parameters. To this effect, for Hertzian contact conditions, we write 


$$
\frac{P(d)}{A_{n}} \propto \delta E^{*}\left(R_{s} R_{q}^{3}\right)^{\frac{1}{2}} \exp \left(-\frac{3 d}{R_{q}}\right)
$$

where $\delta$ is the density of the roughness. As such, to determine which of the skins, human or reptilian, is more likely to be affected by hysteresis, it is sufficient to develop the ratio between the contact pressures affecting the skins under the same nominal load, and assuming common asperity radii Rs, viz,

$$
\frac{N(d)_{H}}{N(d)_{P}} \propto \frac{\delta_{H}}{\delta_{P}} \sqrt{\left(\frac{R_{q H}}{R_{q P}}\right)^{3}} \frac{E_{H}^{*}}{E_{P}^{*}} \exp \left(-3 d\left[\frac{1}{R_{q P}}+\frac{1}{R_{q H}}\right]\right)
$$

Here the subscripts $\mathrm{H}$ and $\mathrm{P}$ denote human and snake skin respectively. Two ratios control the outcome of equation (5). The first is the ratio of the root mean roughness $\mathrm{RqH} / \mathrm{RqP}$ that is a metrological function and is rooted in the topography of each of the skin surfaces. The second ratio meanwhile is the ratio of the composite moduli of the elasticity $\mathrm{E}^{*} \mathrm{H}_{\mathrm{H}} \mathrm{E}^{*} \mathrm{p}$. This implies that at least within the context of our simplifying assumptions the outcome of equation (5) is determined by the level of interaction of the surface structure and the mechanical properties of the particular type of skin. Referring to table (2) and observing the values of the $\mathrm{R}_{\mathrm{q}}$ roughness parameter we note that the most influential term in equation five is the ration $R_{q H} / R_{q P}$ is in the order $23 \leq R_{q H} / R_{q P} \leq 51$.

Measuring the elastic modulus of human skin was a subject of many studies. The values quoted in literature reflect dependency on contact scale, location, and state of hydration. Van Kinelenburg [99] introduced a unified equation that predicts the effective modulus for human skin taking into consideration most of the results reported in literature and likely scale of contact. Using such equation the effective modulus for human skin falls in the interval $1 \mathrm{Mpa}$ $\leq \mathrm{EH}_{\mathrm{H}} \leq 5 \mathrm{Mpa}$. For snakeskin, however, few studies have attempted to measure the elastic modulus for different species. Rivera [100] reported that the elastic modulus for the common garter snake, Thamnophis sirtalis, ranges between $6 \leq \mathrm{E}_{\mathrm{sn}} \leq 12 \mathrm{MPa}$. Using this value along with that for human skin in equation (5) results in a contact pressure for human skin that is at least 10 times that of snakeskin for the same separation distance. This implies that under the same external loads and geometry of contact probe the human skin is more influenced by hysteresis than snakeskin.

\subsection{Coefficient of Friction}

For design purposes, it is essential to quantify the COF regardless of the anatomical site. That is, it is necessary to work with an average value that represents the friction coefficient of the skin. Therefore, we evaluated the overall average of all measurements performed on reptilian skin (i.e., measurements for both snakes used) and compared them to the average coefficient for human skin.

Figure 12 presents a plot of these average quantities. Figure 12-a presents a plot of the average of the measurements obtained in the current work, whereas figure 12-b depicts a plot of the average of the values obtained in the current work and those values reported in literature (summarized in tables 5 and 6). The first plot, figure 12-a, depicts the overall average of the $\mathrm{COF}$ of the skin in dry friction based on measurements obtained in the current work. The plot comprises three bars. The first, labelled human skin represents the average of the COF measurements obtained for all anatomical sites examined. Two bars are included for the skin of the snakes. The first (in light blue) represents the average value for the forward COF $\left(\mu_{\mathrm{f}}\right)$ for both snake species, and all sites examined on the skin. The second bar meanwhile, represents the average value, for the COF in backward motion $\left(\mu_{\mathrm{B}}\right)$. The values imply that the COF for 
human skin is considerably higher than the overall value for the snakeskin (almost four folds). Such a trend is consistent with the order of magnitude of the average heights of the roughness. Recall that the values of the roughness parameters for human skin are higher than the parameters of snakeskin.
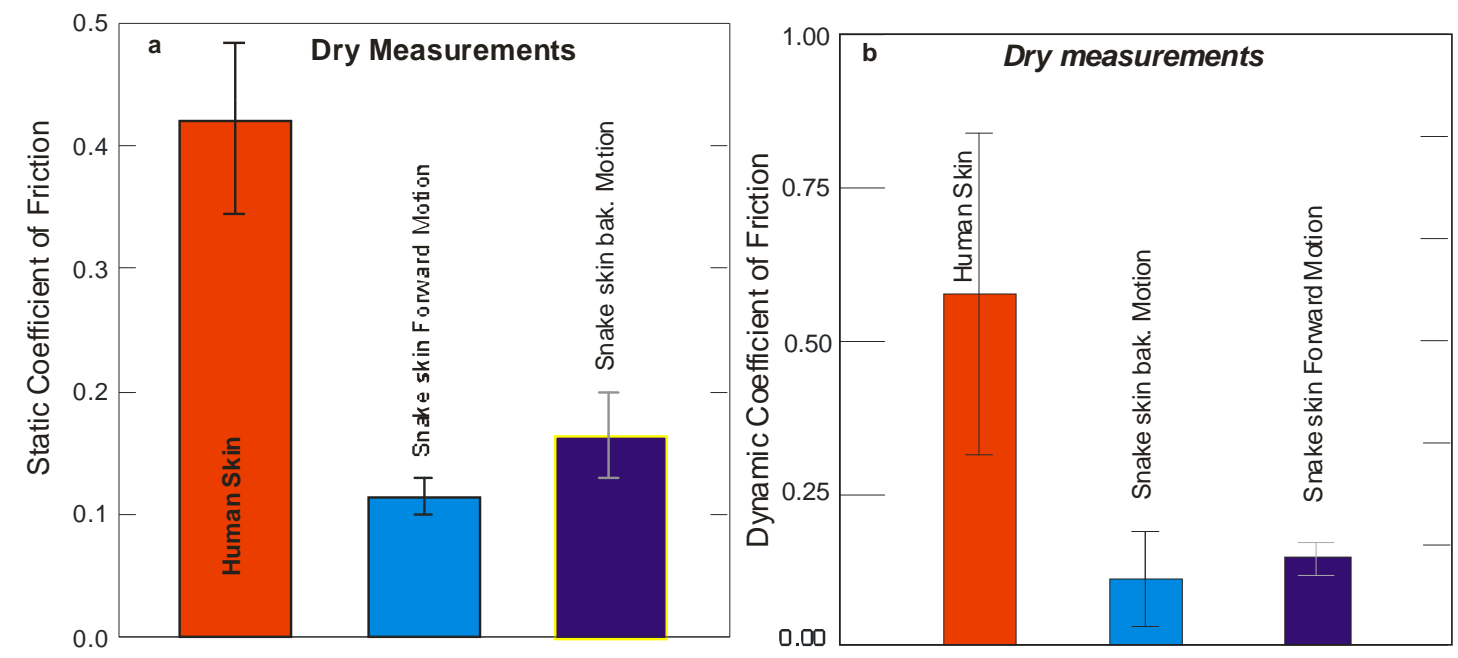

Figure 12 Plot of the average COF for the skins examined in the current work for wet and dry friction (a) plot of the average of the measurements obtained in the current work, (b) depicts a plot of the average of the values obtained in the current work and those values reported in literature (summarized in tables 6 and 7).

\subsection{Dry friction mechanisms}

Dry friction of the skin may be studied by means of Bowden and Tabor two-term model [101]. The model considers the force of friction developed in rubbing of dry skin a superposition of two contributions: an interfacial component, $F_{\text {int }}$, and a deformation component $F_{\text {def. }}$ This yields, the total friction force as,

$$
F=F_{\text {int }}+F_{\text {def }}
$$

The deformation component has its origin in the incomplete recovery of energy dissipated due to deformation of the skin. For many cases involving the friction of polymers and thin films of biomaterials, the deformation component may be ignored and only the interfacial contribution is to be solely considered [102]. The origin of the interfacial component is the dissipation of energy due to rupture of intermittent junctions formed between the two sliding interfaces and deformation of roughness elements. Therefore, we write the interfacial contribution of the friction force as $[103,104]$ in the linear form

$$
F_{f}=F_{a d}=\tau A_{\text {real }}
$$

Where $\tau$ is the interfacial shear stress and Areal is the real area of contact between skin and substrate. The adhesion force $F_{\text {ad }}$ is a function of two contributions, the surface energy of the counter faces and the area over which the adhesive bonds do form [105-107].

As a first approximation, one may model skin behaviour in friction as an elastic deformable material of which interaction with the sliding counter face follows Hertzian theory. It follows that the area of contact $A_{\text {real }}$ in equation (7) is calculated from,

$$
A_{\text {real }}=\pi\left[\frac{3}{4} \frac{R W}{E_{c}}\right]^{\frac{2}{3}}
$$


Where $\mathrm{R}$ is the radius of the contact probe, $\mathrm{W}$ is the applied normal load and $\mathrm{E}_{\mathrm{c}}$ is the composite or reduced Young's Modulus given by,

$$
E_{c}=\left[\left(\frac{1-v^{2}}{E}\right)_{\text {skin }}+\left(\frac{1-v^{2}}{E}\right)_{\text {substrt }}\right]^{-1}
$$

Considering the rigidity of the probe (substrate) compared to the skin, the second term in equation (9) becomes zero. Consequently, the real area of contact $A_{\text {real }}$ is expressed as,

$$
A_{\text {real }}=K\left[\frac{\left(1-v^{2}\right)}{E}\right]^{\frac{2}{3}}(R W)^{\frac{2}{3}}
$$

Where $\mathrm{K}$ is a constant, and the Poisson's ratio and the modulus of elasticity are those of the skin. Recognizing that the COF is the ratio of the friction force to the normal load acting on the skin, we may write

$$
\mu=\frac{\tau A_{\text {real }}}{W}=K \tau\left(\frac{\left(1-v^{2}\right)}{E}\right)^{\frac{2}{3}}\left(\frac{R^{2}}{W}\right)^{\frac{1}{3}}
$$

Under the assumption of elastic behaviour the shear stress $\tau$ in equation (11) may be expressed as,

$$
\tau=\frac{\gamma E}{2(1+v)}
$$

Now consider two skin samples the first is a human sample, $\mathrm{H}$, and the second is that of a snake, denoted by s. If both samples slide under the same shear stress, and against the same interface, then the ratio of their shear strain, again within the elastic solid approximation, takes the form,

$$
\frac{\gamma_{H}}{\gamma_{s}}=\frac{E_{s}\left(1+v_{H}\right)}{E_{H}\left(1+v_{s}\right)}
$$

Using equations (11) and (13) the ratio of the COF for the human skin to the COF of snakeskin simplifies to,

$$
\frac{\mu_{H}}{\mu_{S}} \propto\left(\frac{E_{S}}{E_{H}}\right)^{\frac{2}{3}}\left[\frac{\left(1-v_{H}\right)}{\left(1-v_{S}\right)} \frac{\left(1+v_{H}\right)}{\left(1+v_{S}\right)}\right]^{2 / 3}
$$

Recognizing that the magnitude of the second term in equation (14) is around unity, we deduce the main influence on the ratio of the friction coefficients as,

$$
\frac{\mu_{H}}{\mu_{s}} \propto\left(\frac{E_{S}}{E_{H}}\right)^{\frac{2}{3}}
$$

Equation (15) indicates that the ratio of friction coefficients in dry mode is proportional to the ratio of the moduli of elasticity of the skins. As such, using the values previously used in equation 5 yields the maximum approximate value of the ratio of friction coefficients $\mu_{\mathrm{H}} / \mu_{\mathrm{Sn}}$ as 4.5. Such a value is very close to the ratio of the coefficients calculated from figure (12-a) $\left(\mu_{\mathrm{H}} / \mu_{\mathrm{SnF}} \approx 4.5\right.$ and $\left.\mu_{\mathrm{H}} / \mu_{\mathrm{SnB}} \approx 3\right)$.

It is important to note that the comparison of COF performed to note that the comparison of COF performed in this work is intended as an initial exploration. The behavior of skin in 
friction, regardless of the species, is very complex. The complexity drives from the internal makeup of the skin and the mechanical behavior of the components or layers. As seen in section two, the composition of both human and snake skin entails layers of essentially different composition (chemically and mechanically). These layers are inhomogeneous with respect to the building blocks (fibers, keratin structures, filaments, etc.). The individual components also have different orientations. This complexity of construction definitely reflects on the tribological behavior of the skin and for sure reflects on the mechanical properties of the skin. Each layer of the skin has its own mechanical properties. Detailed analysis of friction response of human skin for example [108, 109] showed that the outer layer of the skin, the stratum corneum, has a dominant influence. This layer, however, does not act individually but supports the loads through assistance from the underlying strata of the skin (each contributing according to the mechanical properties).

Behavior of snakeskin is not drastically different as the outer layer, the Oberhautchen, contains the topographical features of the skin, whence it dominates friction. Similar to human skin, it supports loads in conjunction with the underlying layers of the skin and the musculature involved. In all, the detailed picture concerning the response of skin to friction does not lend itself to simple analysis. As such, in this work we sought a generalized framework that seeks the features common in behavior of the two skin types.

The analysis presented here mainly dealt with dry sliding. For sliding in presence of moisture, other effects have to be considered (e.g. surface energy of the skin). Many of the necessary parameters are not uniquely characterized for human skin. The literature is full of different, sometimes contradicting, values for properties of human skin in wet state. For snakeskin, the situation is more undefined. There is a complete vacuum when mechanical properties are considered. However, some experimental work, which is in preparation and performed in the first author's lab, indicates similarity in behavior between human skin and snakeskin when sliding in wet mode. In particular, the COF for wet snakeskin increases, compared to the dry $\mathrm{COF}$, in the presence of moisture which is similar to the behavior of wet human skin reported elsewhere [67-81].

The COF model presented in this work has its origin in Hertzian contact mechanics. One way of modelling the contact mechanics involved is that of studying a punch, which represents the roughness feature of the substrate, initially penetrating through the skin. The mechanical response of the skin surface will depend on the depth that an asperity penetrates through the skin. Hill [110], motivated by early experimental and theoretical works [111-115], developed a so-called similarity solution for rigid indentation, that which models the examined contact situation. He showed that the overall solution of the contact mechanics problem, whence the normal and tangential forces resulting could be derived from a single solution given that appropriate scaling is adopted. That is the geometry, stress and strain fields throughout the indentation process are derived from a power law relationship [115-117].

The conclusions reached herein should be accepted only in the context of the experimental condition prevailing in the current work. We examined human skin with all compositional layers involved in friction (despite the apparent notion that only the superficial layer, the "dermis", is in direct contact with the triboprobe. Snake shedskin samples, however, comprised only the outer layers of the skin without the sublayers that typically support the skin in a life reptile. Such a situation affects the deformation and viscoelastic dissipation contributions to friction of both skins.

The lateral friction force in the two-term model invoked in this work is in essence a superposition of an adhesive component and a deformation component. The adhesion component is a consequence of interfacial shear and the deformation component originates 
from the energy dissipated by subsurface viscoelastic deformation especially at the front of the probe. The subsurface deformation also entails viscoelastic stretching, or hysteresis, in the lateral direction (i.e. lateral skin stretching). The stretching is to be noted takes place within all subsurface supporting layers of the skin. Naturally, within the constraints of the current work, dissipation within the human skin samples involved those supporting layers since the measurements were performed in situ. For snakeskin, however, dissipation did not involve such layers. That is, lateral and tangential dissipation in case of snakeskin was not activated. This situation indicates a discrepancy between the amounts of energy dissipated due to deformation in each of the examined skins. The exact effect of this discrepancy on the accuracy of the numerical values of the COF ratio was not attempted here. However, it is estimated that this effect will not have a considerable effect on the trend reflected in the current work for two reasons. The first is that the deformation contribution to the COF is typically negligible (in the order of 0.04 to 0.06 [102]). The second meanwhile has to do with the high fractal dimension of both skins $\mathrm{D} \geq 2.55$ [60], which indicate that the behavior of the material in friction is dominated by the mechanical properties of the surface features rather than those of the bulk of the material.

\section{Conclusions}

The primary motivation of this study is to explore the similarities in friction response of various skin types. This work, therefore, introduced, for the first time in tribology literature, a crosscorrelation study of the behaviour of two different skin types (human and snake) in dry friction. The premise of the work originates from the similarity of the stress-strain curve obtained in tensile testing of skin across species (i.e. the so-called J-type curve) and from the similarity of the building blocks of skin across species (fibres and elastin). Combined to the welldocumented influence of mechanical properties on tribological behaviour of materials, the existence of a common stress-strain curve may suggest the existence of a generalized framework that can describe, and then predict, the friction behaviour of skin in general.

The analysis invoked the conventional two-term friction model to correlate the friction coefficient of human skin to that of snakeskin. In doing so we have introduced the simplifying assumption of elastic behaviour as a first approximation. Within such frame of reference the ratio of the $\mathrm{COF}$, snake to human, correlated to the inverse ratio of the respective moduli raised to a fraction exponent.

The results, albeit preliminary and under simplifying conditions, imply that dominant mechanisms in dry friction of both skins are similar. In particular, the dominance of the moduli of elasticity implies the principal importance of frictional energy dissipation-accumulation for structural integrity of the skin building blocks.

Future work will be directed toward the comparison of wet friction performance for both types of skin and to widen the scope of investigation to include in vitro reptilian skin measurements and skin from other species.

\section{References}

[1] Vincent JF. Structural biomaterials. Princeton University Press; 2012.

[2] Wainwright SA. Mechanical design in organisms. Princeton University Press; 1982.

[3] Mai YW, Atkins AG. Further comments on J-shaped stress-strain curves and the crack resistance of biological materials. Journal of physics D: Applied physics. 1989 Jan 14;22(1):48.

[4] Dowson D. Tribology and the skin surface. Bioengineering of the skin: Skin surface imaging and analysis. 1996 Dec 3:159-79.

[5] Timm K, Myant C, Spikes HA, Grunze M. Particulate lubricants in cosmetic applications. Tribology International. 2011 Nov 30;44(12):1695-703. 
[6] Abramovits W, Gonzalez-Serva A. Sebum, cosmetics, and skin care. Dermatologic clinics. 2000 Oct 1;18(4):617-20.

[7] Bhushan B, Tang W. Surface, tribological, and mechanical characterization of synthetic skins for tribological applications in cosmetic science. Journal of applied polymer science. 2011 Jun 5;120(5):2881-90.

[8] Bhushan B, Wei G, Haddad P. Friction and wear studies of human hair and skin. Wear. 2005 Aug 31;259(7):1012-21.

[9] Korinko A, Yurick A. Maintaining skin integrity during radiation therapy. AJN The American Journal of Nursing. 1997 Feb 1;97(2):40-4.

[10] Herst PM. Protecting the radiation-damaged skin from friction: a mini review. Journal of medical radiation sciences. 2014 Jun 1;61(2):119-25.

[11] Rogachefsky AS, Taylor JS. Professional sports: Skin disorders in athletes. InHandbook of Occupational Dermatology 2000 (pp. 1072-1083). Springer Berlin Heidelberg.

[12] Zhang M, Mak AF. In vivo friction properties of human skin. Prosthetics and orthotics international. 1999 Jan 1;23(2):135-41.

[13] Derler S, Preiswerk M, Rotaru GM, Kaiser JP, Rossi RM. Friction mechanisms and abrasion of the human finger pad in contact with rough surfaces. Tribology International. 2015 Sep 30;89:119-27.

[14] Mak AF, Zhang M, Boone DA. State-of-the-art research in lower-limb prosthetic biomechanics-socket interface: a review. Journal of rehabilitation research and development. 2001 Mar 1;38(2):161.

[15] Zhang M, Roberts C. Development of a nonlinear finite element model for analysis of stump/socket interface stresses in below-knee amputee. WIT Transactions on Biomedicine and Health. 1970 Jan 1;1.

[16] Filep R, Arotaritei D, Turnea M, Ilea M, Rotariu M, Budacu C. A viscoelastic model for skin of stump in transtibial prosthesis. Proceedings in Manufacturing Systems. 2016 Mar 1;11(1):35.

[17] Derler S, Gerhardt LC. Tribology of skin: review and analysis of experimental results for the friction coefficient of human skin. Tribology Letters. 2012 Jan 1;45(1):1-27.

[18] Schreiner S, Rechberger M, Bertling J. Haptic perception of friction-correlating friction measurements of skin against polymer surfaces with subjective evaluations of the surfaces' grip. Tribology International. 2013 Jul 31;63:21-8.

[19] Tang W, Chen N, Zhang J, Chen S, Ge S, Zhu H, Zhang S, Yang H. Characterization of tactile perception and optimal exploration movement. Tribology Letters. 2015 May 1;58(2):1-4.

[20] Darden MA, Schwartz CJ. Skin tribology phenomena associated with reading braille print: The influence of cell patterns and skin behavior on coefficient of friction. Wear. 2015 Jun 30;332:734-41.

[21] Yoon WJ, Hwang WY, Perry JC. Study on effects of effects of surface properties in haptic perception of virtual curvature. International Journal of Computer Applications in Technology. 2016;53(3):236-43.

[22] Gerhardt LC, Strässle V, Lenz A, Spencer ND, Derler S. Influence of epidermal hydration on the friction of human skin against textiles. Journal of The Royal Society Interface. 2008 Nov 6;5(28):1317-28.

[23] Hendriks CP, Franklin SE. Influence of surface roughness, material and climate conditions on the friction of human skin. Tribology Letters. 2010 Feb 1;37:361-73. 
[24] Derler S, Huber R, Feuz HP, Hadad M. Influence of surface microstructure on the sliding friction of plantar skin against hard substrates. Wear. 2009 Jun 15;267:1281-8.

[25] Guerra C, Schwartz CJ. Investigation of the influence of textiles and surface treatments on blistering using a novel simulant. Skin Research and Technology. 2012 Feb 1;18(1):94-100.

[26] Soneda T, Nakano K. Investigation of vibrotactile sensation of human fingerpads by observation of contact zones. Tribology International. 2010 Feb 28;43(1):210-7.

[27] Frackiewicz-Kaczmarek J, Psikuta A, Bueno MA, Rossi RM. Air gap thickness and contact area in undershirts with various moisture contents: influence of garment fit, fabric structure and fiber composition. Textile Research Journal. 2015 Mar 26:0040517514551458.

[28] Van Der Heide E, Lossie CM, Van Bommel KJ, Reinders SA, Lenting HB. Experimental investigation of a polymer coating in sliding contact with skin-equivalent silicone rubber in an aqueous environment. Tribology Transactions. 2010 Oct 6;53(6):842-7.

[29] Cottenden DJ, Cottenden AM. A study of friction mechanisms between a surrogate skin (Lorica soft) and nonwoven fabrics. Journal of the mechanical behavior of biomedical materials. 2013 Dec 31;28:410-26.

[30] Bostan LE, Taylor ZA, Carré MJ, MacNeil S, Franklin SE, Lewis R. A comparison of friction behaviour for ex vivo human, tissue engineered and synthetic skin. Tribology International. $2016 \mathrm{Jul} 28$.

[31] Gerhardt LC, Schiller A, Müller B, Spencer ND, Derler S. Fabrication, characterisation and tribological investigation of artificial skin surface lipid films. Tribology letters. 2009 May 1;34(2):81-93.

[32] Wang Z, Jiang F, Zhang Y, You Y, Wang Z, Guan Z. Bioinspired Design of Nanostructured Elastomers with Cross-Linked Soft Matrix Grafting on the Oriented Rigid Nanofibers To Mimic Mechanical Properties of Human Skin. ACS nano. 2014 Dec 31;9(1):271-8.

[33] Nachman M, Franklin SE. Artificial Skin Model simulating dry and moist in vivo human skin friction and deformation behaviour. Tribology International. 2016 May 31;97:431-9.

[34] H. Shirado, Y. Nonomura and T. Maeno: Development of artificial skin having human skin-like texture (realization and evaluation of human skin-like texture by emulating surface shape pattern and elastic structure), Trans. Jpn. Soc. Mech. Eng. C, 73-726, 541/546 (2007)

[35] Chen S, Bhushan B. Nanomechanical and nanotribological characterization of two synthetic skins with and without skin cream treatment using atomic force microscopy. Journal of colloid and interface science. 2013 May 15;398:247-54.

[36] Lijie HF, Pan LH. Study on Tribological Behaviors of Porcine Serum in Water-soluble Polyalkylene Glycol and Water. Lubrication Engineering. 2009;1:025.

[37] Xiao H, Ariyasinghe N, He X, Liang H. Tribological evaluation of porcine skin. Colloids and Surfaces B: Biointerfaces. 2014 Apr 1;116:734-8.

[38] Benz MJ, Kovalev AE, Gorb SN. Anisotropic frictional properties in snakes. InSPIE Smart Structures and Materials+ Nondestructive Evaluation and Health Monitoring 2012 Apr 26 (pp. 83390X-83390X). International Society for Optics and Photonics.

[39] Abdel-Aal HA, El Mansori M, Mezghani S. Multi-scale investigation of surface topography of ball python (Python regius) shed skin in comparison to human skin. Tribology letters. 2010 Mar 1;37(3):517-27. 
[40] Abdel-Aal HA, Vargiolu R, Zahouani H, El Mansori M. A study on the frictional response of reptilian shed skin. Journal of Physics: Conference Series 2011 (Vol. 311, No. 1, p. 012016). IOP Publishing.

[41] Abdel-Aal HA, El Mansori M. Characterization of load bearing metrological parameters in reptilian exuviae in comparison to precision-finished cylinder liner surfaces. Surface Topography: Metrology and Properties. 2014 Oct 23;2(4):045002.

[42] Klein MC, Gorb SN. Ultrastructure and wear patterns of the ventral epidermis of four snake species (Squamata, Serpentes). Zoology. 2014 Oct 31;117(5):295-314.

[43] Godin B, Touitou E , 2007. Transdermal skin delivery: predictions for humans from in vivo, ex vivo and animal models Adv Drug Deliv Rev 59(11), 1152-61

[44] G.M. Gray, H.J. Yardley, 1975. Lipid compositions of cells isolated from pig, human, and rat epidermis, J. Lipid Res. 16, 434-440.

[45] U. Jacobi, M. Kaiser, R. Toll, S. Mangelsdorf, H. Audring, N. Otberg, W. Sterry, Lademann 2007. Porcine ear skin: an in vitro model for human skin, Skin Res. Technol. 13, 19-24.

[46] I.P. Dick, R.C. Scott, 1992. Pig ear skin as an in-vitro model for human skin permeability, J. Pharm. Pharmacol. 44, 640-645.

[47] F. Muhammad, J.D. Brooks, J.E. Riviere, 2004Comparative mixture effects of JP$8(100)$ additives on the dermal absorption and disposition of jet fuel hydrocarbons in different membrane model systems, Toxicol. Lett. 150, 351-365.

[48] Lin SY, Hou SJ, Hsu TH, Yeh FL., 1992. Comparisons of different animal skins with human skin in drug percutaneous penetration studies. Methods Find Exp Clin Pharmacol. Oct;14(8), 645-54.

[49] F. Netzlaff, U.F. Schaefer, C.M. Lehr, P. Meiers, J. Stahl, M. Kietzmann, F. Niedorf, 2006. Comparison of bovine udder skin with human and porcine skin in percutaneous permeation experiments, Altern. Lab. Anim. 34, 499-513.

[50] Sandby-Moller, J., Poulsen, T., H.C. Wulf, Epidermal thickness at different body sites: relationship to age, gender, pigmentation, blood content, skin type and smoking habits, Acta Derm.-Venereol. 83 (2003) 410-413.

[51] Simon, G.A., Maibach, H.I., 2000. The pig as an experimental animal model of percutaneous permeation in man: qualitative and quantitative observations an overview, Skin Pharmacol. Appl. Skin Physiol. 13, 229-234.

[52] Higuchi, T., L. Kans, 1988. Method for in vitro determination of transdermal absorption. United States Patent, Patent number 4771004, 13 Sep.

[53] Itoh, T., J. Xia, R. Magavi, T. Nishisata, J.H. Rytting, 1990a. Use of shed skin as a model membrane for invitro percutaneous penetration studies: comparison with human skin. Pharm. Res., 7, 1042-1047.

[54] Bhattachar, S.N., J.H. Rytting, T. Itoh, T. Nishihata, 1992. The effects of complexation with hydrogenated phospholipid on the transport of salicylic acid, diclofenac and indomethacin across snake stratum corneum. Int. J. Pharm., 79: 263-271.

[55] Bhatt, P.P., J.H. Rytting, E.M. Topp, 1991. Influence of azone and lauryl alcohol on the transport of acetaminophen and ibuprofen through shed snake skin.Int. J. Pharm., 72: 219-226.

[56] Harada, K., T. Murakami, E. Kawasaka, Y. Higashi, S. Yamanoyo and N. Yata, , 1993. In vitro permeability to salicylic acid of human, rodent and shed snake skin. J. Pharm. Pharmacol., 45, 414-418. 
[57] Pongjanyakul, T., S. Prakongpan, S. Panomsuk, S. Puttipipatkhachorn and A. Priprem, 2002. Shed king cobra and cobra skins as model membranes for in-vitro nicotine permeation studies. J. Pharm. Pharmacol., 54, 1345-1350.

[58] Haigh, J.M., E. Beyssac, L. Chanet and J.M. Aiache, 1998. In vitro permeation of progesterone from a gel through the shed skin of three different snake species. Int. J. Pharm., 170, 151-156.

[59] Turunen, T.M., S. Buyuktimkin, N. Buyuktimkin, A. Urtti, P. Paronen and J.H. Rytting, Enhancer delivery of 5-fluorouracil through shed snake skin by two transdermal penetration enhancers. 1993. Int. J. Pharm. 92, 89-95.

[60] Abdel-Aal, H. A., El Mansori, M. The Fractal Structure of the Ventral Scales in Legless Reptiles, 15th International Conference on Metrology and Properties of Engineering Surfaces, March 2-5, 2015, UNC Charlotte, Charlotte, North Carolina, USA

[61] Rossi, J.V. 1996. Dermatology. In: Reptile Medicine and Surgery. Douglas R. Mader, editor. WB Saunders, NY. $104-117$.

[62] Alexander, N.J., Parakkal. P.F., 1969. Formation of a- and ß-type keratin in lizard epidermis during the molting cycle. Cell and Tissue Research (Historical Archive)101, 72.

[63] Subramanyan, K., Misra, M., Mukherjee, S., Ananthapadmanabhan,, K.: Advances in the materials science of skin: a composite structure with multiple functions. MRS Bull. 32(10), 770-778 (2007)

[64] Agache, P., Humbert, P. 2004. Measuring the Skin-Non-Invasive Investigations, Physiology, Normal Constants, 1st edn. Springer- Verlag, Berlin

[65] Elsner, P.: What textile engineers should know about the human skin. Curr. Probl. Dermatol. 31, 24-34 (2003)

[66] Klein, M-C. G, Deuschle, J.,Gorb S. N.,, 2010. Material properties of the skin of the Kenyan sand boa Gongylophis colubrinus (Squamata, Boidae). J. of Comp. Phys. A: Neuroethology, Sensory, Neural, and Behav. Phys., 196: 659-68.

[67] Klein, M-C. G., Gorb, S N., Epidermis architecture and material properties of the skin of four snake species J. R. Soc. Interface rsif 20120479; 2012, doi:10.1098/rsif.2012.0479 1742-5662

[68] Pailler-Mattei, C., Nicoli, S., Pirot, E., Vargiolu, R. and Zahouani, H., "A new approach to describe the skin surface physical properties in vivo", Colloid Surf; 68: 200-206, 2009.

[69] Cua, A. B., Wilheim, K. P. and Maibach, H. I. 1990. Friction Properties of Human Skin: Relation to Age, Sex and Anatomical Region, Stratum Corneum Hydration and Transepidermal Water Loss,Brit. J. Dermatol., 123, 473-479.

[70] Elsner, P., Wilhelm, D. and Maibach, H. I., 1990, Friction Properties of Human Forearm and Vulvar Skin: Influence of Age and Correlation with Transepidermal Water Loss and Capacitance.Dermatologica, 181, 88-91.

[71] Asserin J., Zahouani H., Humbert Ph. Couturaud V., Mougin D., 2000. Measurement of the friction coefficient of the human skin in vivo Quantification of the cutaneous smoothness; Colloids and Surfaces B: Biointerfaces 19:1-12.

[72] Manuskiatti WD, Schwindt DA, Maibach HI. Influence of age, anatomic site and race on skin roughness and scaliness. Dermatology. 1998 Jun 26;196(4):401-7.

[73] Berthé, R. A., Westhoff, G., Bleckmann, H., Gorb, S. N., 2009. Surface structure and frictional properties of the skin of the Amazon tree boa Corallus hortulanus (Squamata Boidae) J. Comp. Phys. A 195: 311-318. 
[74] Shafiei, M., Alpas, A. T., 2008. Fabrication of biotextured nanocrystalline nickel films for the reduction and control of friction. Mat. Sc. and Eng.: C; 28: 1340-1346.

[75] Shafiei, M., Alpas, A. T., 2009 Nanocrystalline nickel films with lotus leaf texture for superhydrophobic and low friction surfaces App. Surface Science 256: 710-719.

[76] Abdel-Aal, H. A., Vargiolu, R., Zahouani, H., El Mansori, M., 2012. Preliminary investigation of the frictional response of reptilian shed skin Wear 290-291, 51-60 doi./10.1016/j.wear.2012.05.015

[77] Berthé, R. A., Westhoff, G., Bleckmann, H., Gorb, S. N., 2009. Surface structure and frictional properties of the skin of the Amazon tree boa Corallus hortulanus (Squamata Boidae) J. Comp. Phys. A 195: 311-318.

[78] Abdel-Aal, H. A., 2013. On Surface Structure and Friction Regulation in Reptilian Locomotion, JMBBM 22:115-135, DOI 10.1016/j.jmbbm.2012.09.014

[79] Comaish, S. and Bottoms, E. 1971. The Skin and Friction: Deviations from Amonton's Laws, and the Effects of Hydration and Lubrication, Brit. J. Dermatol., 84, 37-43.

[80] Naylor, P. F. D. (1955), “The Skin Surface and Friction,” Bri. J. Dermatol., 67, 239248.

[81] Prall, J. K. (1973), "Instrumental Evaluation of the Effects of Cosmetic Products on Skin Surfaces with Particular Reference to Smoothness,” J. Soc. Cosmet. Chem., 24, 693-707.

[82] Johnson, S. A., Gorman, D. M., Adams, M. J. and Briscoe, B. J. (1993), “The Friction and lubrication of Human Stratum Corneum," Thin Films in Tribology, Eds. Dowson,D. et al., Proc. 19th Leeds-Lyon Symp. on Trib., Elsevier Science Publishers, B. V., 663-672.

[83] Li, W., Kong, M., Liu, X.D., Zhou, Z.R.: Tribological behavior of scar skin and prosthetic skin in vivo. Tribol. Int. 41(7), 640-647 (2008)

[84] Elleuch, K., Elleuch, R., Zahouani, H.: Comparison of elastic and tactile behavior of human skin and elastomeric materials through tribological tests. Polym. Eng. Sci. 46(12), 1715-1720 (2006)

[85] Gupta, A.B., Haldar, B., Bhattacharya, M.: A simple device for measuring skin friction. Ind. J. Dermatol. 40(3), 116-121 (1995)

[86] Nakajima, K., Narasaka, H.: Evaluation of skin surface associated with morphology and coefficient of friction. Int. J. Cosmet. Sci 15, 135-151 (1993)

[87] Sivamani, R.K., Goodman, J., Gitis, N.V., Maibach, H.I.: Coefficient of friction: tribological studies in man-an overview. Skin Res. Technol. 9(3), 227-234 (2003)

[88] Egawa, M., Hirao, T. and Takahashi, M., "In vivo estimation of Stratum corneum thickness from water concentration profiles obtained with Raman spectroscopy", Acta Derm Venereol; 87: 4-8, 2007.

[89] Christensen, M.S., Nacht, S., Packman, E.W. 1983: Facial oiliness and dryness: correlation between instrumental measurements and self-assessment. J. Soc. Cosmet. Chem. 34(5), 241-253

[90] Hendriks, C. P. and Franklin, S. E., "Influence of Surface Roughness, Material and Climate Conditions on the Friction of Human Skin", Tribol Lett; 37: 361-375, 2010.

[91] Ramalho, A., Silva, C. L., Pais, A. A. C. C. and Sousa, J. J. S., "In-vivo friction study of human skin: influence of moisturizers on different anatomical sites", Wear; 263: 1044-1049, 2007.

[92] Roberts, A. D. and Brackley, C. A. Friction of surgeons' gloves. J. Phys.: Appl. Phys., 1992, 25, A28-A32. 37 
[93] Gee, M.G., Tomlins, P., Calver, A., Darling, R.H., Rides, M.: A new friction measurement system for the frictional component of touch. Wear 259(7-12), 14371442 (2005)

[94] Skedung, L., Danerlo“v, K., Olofsson, U., Aikala, M., Niemi, K., Kettle, J., Rutland, M.: Finger friction measurements on coated and uncoated printing papers. Tribol. Lett. 37(2), 389-399 (2010)

[95] Childs, T.H.C., Henson, B., 2007. Human tactile perception of screen printed surfaces: self-report and contact mechanics experiments. Proc. Inst. Mech. Eng. J. 221(J3), 427441

[96] Savescu, A.V., Latash, M.L., Zatsiorsky, V.M.: A technique to determine friction at the fingertips. J. Appl. Biomech. 24(1), 43-50 (2008)

[97] Greenwood JA, Williamson JB. Contact of nominally flat surfaces. In Proceedings of the Royal Society of London A: Mathematical, Physical and Engineering Sciences 1966 Dec 6 (Vol. 295, No. 1442, pp. 300-319). The Royal Society.

[98] Shi X, Polycarpou AA. Measurement and modeling of normal contact stiffness and contact damping at the meso scale. Journal of vibration and acoustics. 2005 Feb $1 ; 127(1): 52-60$.

[99] van Kuilenburg J, Masen MA, van der Heide E. Contact modelling of human skin: what value to use for the modulus of elasticity?. Proceedings of the institution of mechanical engineers, Part J: Journal of Engineering Tribology. 2013 Apr 1;227(4):349-61.

[100] Rivera G, Savitzky A H., Hinkley J. A., Mechanical properties of the integument of the common gartersnake, Thamnophis sirtalis (Serpentes: Colubridae), J Exp Biol 2005 208:2913-2922. ; doi:10.1242/jeb.01715

[101] Bowden, F. P. and Tabor, D., Friction and Lubrication of Solids, Oxford University Press, London, 1954.

[102] Adams, M. J., Briscoe, B. J. and Johnson, S. A., "Friction and lubrication of human skin", Tribology Letter ; 26; 3, 2007.

[103] Johnson, S. A., Gorman, D. M., Adams, M. J. and Briscoe, B. J. (1993), "The Friction and lubrication of Human Stratum Corneum," Thin Films in Tribology, Eds. Dowson,D. et al., Proc. 19th Leeds-Lyon Symp. on Trib., Elsevier Science Publishers, B. V., 663-672.

[104] Han, H. Y., Shimada, A. and Kawamura, S., "Analysis of friction on human fingers and design of artificial fingers", In IEEE International Conference on Robotics and Automation, Minneapolis, Minnesota; 3061-3066, 1996.

[105] Tomlinson, S. E., Lewis, R. and Carré, M .J., "The effect of normal force and roughness on friction in human finger contact", Wear; 267: 1311-1318, 2009.

[106] Mossel, W. P. and Roosen, C. P. G., "Friction and the skin", Contemporary Ergonomics; 1: 353-358, 1994.

[107] Tang, W., Ge, S. R., Zhu, H., Cao, X. C. and Li, N., "The influence of normal load and sliding speed on frictional properties of skin", Journal of bionic engineering; 5: 33-38, 2008.

[108] Zahouani, H., Boyer, G., Pailler-Mattei, C., Tkaya, M. B. and Vargiolu, R., "Effect of human aging on skin rheology and tribology", Wear; 271: 2364-2369, 2011.

[109] Pailler-Mattei, C., Guerret-Piécourt, C., Zahouani, H. and Nicoli, S., "Interpretation of the human skin biotribological behaviour after tape stripping”, J R Soc Interface; 8: 934-941, 2011.

[110] Hill, R., Stor ${ }^{\circ}$ akers, B. \& Zdunek, A. B. 1989 A theoretical study of the Brinell hardness test. Proc. R. Soc. Lond. A436, 301-330. 
[111] Meyer, E. 1908 Untersuchungen "uber Harteprufung und Harte. Z. Ver. Deutche Ing. $52,645-654$.

[112] O'Neill, H. 1944 The significance of tensile and other mechanical test properties of metals. Proc. Inst. Mech. Engineers 151, 116-130.

[113] Tabor, D. 1951 The hardness of metals. Oxford University Press.

[114] Norbury, A. L. \& Samuel, T. 1928 The recovery and sinking-in or piling-up of material in the Brinell test, and the e ects of these factors on the correlation of the Brinell with certain other hardness tests. J. Iron Steel Institute 117, 673-687

[115] Timothy, S. P., Pearson, J. M. \& Hutchings, I. M. 1987 The contact pressure distribution during plastic compression of lead spheres. Int. J. Mech. Sci. 29, 713719.

[116] Bower, A. F., Fleck, N. A., Needleman, A. \& Ogbonna, N. 1993 Indentation of power law creeping solids. Proc. R. Soc. Lond. A441, 97-124

[117] Biwa, S. \& Stor ${ }^{\circ}$ akers, B. 1995 An analysis of fully plastic Brinell indentation. J. Mech. Phys. Solids 43, 1303-1334. 